CONTRATO DE APRENDIZAGEM: FUNDAMENTOS, POSSIBILIDADES E LIMITES À LUZ DA EVOLUÇÃO DO DIREITO À EDUCAÇÃO

\author{
Dissertação de Mestrado \\ Orientador: Professor Associado Dr. Enoque Ribeiro dos Santos
}

UNIVERSIDADE DE SÃO PAULO

FACULDADE DE DIREITO

São Paulo - SP

2019 

BRUNO GONÇALVES VAICIULIS

\title{
CONTRATO DE APRENDIZAGEM: FUNDAMENTOS, POSSIBILIDADES E LIMITES À LUZ DA EVOLUÇÃO DO DIREITO À EDUCAÇÃO
}

\begin{abstract}
Dissertação apresentada à Banca Examinadora do Programa de Pós-Graduação em Direito, da Faculdade de Direito da Universidade de São Paulo, como exigência parcial para obtenção do título de Mestre em Direito, na área de concentração Direito do Trabalho e da Seguridade Social, sob a orientação do Professor Associado Dr. Enoque Ribeiro dos Santos.
\end{abstract}

UNIVERSIDADE DE SÃO PAULO

FACULDADE DE DIREITO

São Paulo - SP

2019 


\section{Catalogação na Publicação \\ Serviço de Processos Técnicos da Biblioteca da \\ Faculdade de Direito da Universidade de São Paulo}

Vaiciulis, Bruno Gonçalves

Contrato de aprendizagem: fundamentos, possibilidades e limites à luz da evolução do direito à educação / Bruno Gonçalves Vaiciulis. -- São Paulo, 2019.

244 p. ; $30 \mathrm{~cm}$.

Dissertação (Mestrado) - Programa de Pós-Graduação em Direito, Faculdade de Direito, Universidade de São Paulo, São Paulo, 2019.

Orientador: Enoque Ribeiro dos Santos

1. Contrato de aprendizagem. 2. Direito do Trabalho. 3. Formação técnico-profissional metódica. I. Santos, Enoque Ribeiro dos, orient. II. Título. 
Nome: Vaiciulis, Bruno Gonçalves.

Título: Contrato de aprendizagem: fundamentos, possibilidades e limites à luz da evolução do direito à educação.

Dissertação apresentada à Banca Examinadora do Programa de Pós-Graduação em Direito, da Faculdade de Direito da Universidade de São Paulo, como exigência parcial para obtenção do título de Mestre em Direito, na área de concentração Direito do Trabalho e da Seguridade Social, sob a orientação do Professor Associado Dr. Enoque Ribeiro dos Santos.

Aprovado em:

Banca Examinadora:

Prof. Dr.

Julgamento:

Prof. Dr.

Julgamento:

Prof. Dr.

Julgamento:

Prof. Dr.

Julgamento:
Instituição:

Assinatura:

Instituição:

Assinatura:

Instituição:

Assinatura:

Instituição:

Assinatura: 

Aos meus pais, Sérgio e Maria. 



\section{Agradecimentos}

Agradeço à minha família, pelo incondicional apoio no caminho da vida.

Agradeço também ao Prof. Enoque Ribeiro dos Santos, pela orientação cuidadosa e paciente e também pela atenção dispensada à minha pesquisa. Muito obrigado professor, por ter aceitado me orientar neste trabalho tão importante para a minha vida.

Não poderia deixar de agradecer também à Prof ${ }^{a}$. Kimi Aparecida Tomizaki (FEUSP) e ao Prof. Roberto da Silva (FE-USP), que me ajudaram a encontrar respostas para minhas dúvidas relacionadas à educação profissional.

Meus agradecimentos também à biblioteca da Faculdade de Educação da Universidade de São Paulo e aos seus zelosos servidores.

Outrossim, agradeço à minha querida Faculdade de Direito da Universidade de São Paulo, onde concluí a minha graduação e agora pude prosseguir em meus estudos acadêmicos. 



\section{RESUMO}

Bruno Gonçalves Vaiciulis. Contrato de aprendizagem: fundamentos, possibilidades e limites à luz da evolução do direito à educação. 2019. 244 p. Mestrado - Faculdade de Direito, Universidade de São Paulo, São Paulo, 2019.

O presente trabalho tem por objetivo analisar os fundamentos, as possibilidades e os limites de pactuação do contrato de aprendizagem, considerando principalmente a sua prestação educativa e o direito à educação. Primeiramente, fizemos uma análise histórica do instituto, cujas origens remontam às corporações de ofício medievais. Observamos que o instituto sofreu profundas transformações com a industrialização e foi tipificado no Brasil, sob influência da doutrina taylorista de organização racional do trabalho. A Consolidação das Leis do Trabalho - CLT é o diploma legal que disciplina o contrato de aprendizagem. A partir da legislação aplicável ao contrato, expusemos e analisamos elementos caracterizadores da relação de aprendizagem e elementos que são peculiaridades da tipificação do contrato, no Brasil. Observamos que a legislação celetista é muito sucinta na disciplina do conteúdo dos programas de aprendizagem, utilizando a expressão "formação técnico-profissional metódica" para se referir à prestação educativa do contrato. Analisamos a prestação educativa com fundamento na doutrina e também nas normas infralegais aplicáveis ao contrato. Constatamos que os programas de aprendizagem podem comportar diversos cursos e programas de educação profissional. Estabelecemos, assim, um diálogo entre a legislação trabalhista e a legislação educacional. Analisamos também algumas questões correlatas à aprendizagem, como os níveis de educação no Brasil, a dualidade histórica entre educação geral e educação profissional, a idade para a educação escolar e a idade para o trabalho, o trabalho infantil e o trabalho educativo previsto no Estatuto da Criança e do Adolescente - ECA. Por fim, analisamos brevemente as transformações pelas quais passou a aprendizagem, a partir das alterações realizadas na CLT, pela Lei $n^{\circ}$ 10.097/2000. A aprendizagem passa a ser instrumento de uma política pública, que objetiva a concretização dos direitos ao trabalho, à profissionalização e à educação, destinada prioritariamente aos adolescentes entre quatorze e dezoito anos, mas aberta também às pessoas que possuem até vinte e quatro anos idade.

Palavras-chave: Contrato de aprendizagem, Aprendizagem, Formação técnico-profissional metódica, Educação profissional. 



\begin{abstract}
Bruno Gonçalves Vaiciulis. Apprenticeship contract: fundamentals, possibilities and limits in the light of the evolution of right to education. 2019. 244 p. Master - Faculty of Law, University of São Paulo, São Paulo, 2019.
\end{abstract}

The present study aims to analyze foundations, possibilities and limits of apprenticeship contract, considering mainly its educational provision and the right to education. First, We did a historical analysis of the Institute whose origins date back to medieval craft corporations. We noted that the institute has undergone profound changes in industrialization and it has been typified in Brazil under the influence of the Taylor doctrine of rational organization of the work. The Consolidation of Labor Laws - CLL is the legal diploma that governs the apprenticeship contract. Under applicable legislation to the contract, we have exposed and analyzed elements that characterized the apprenticeship relationship and elements that are peculiarities of the typification of the contract in Brazil. We observe that the legislation is very succinct as for the discipline of the apprenticeship programs contents, using the term "technical and vocational methodical training" referring to the educational performance of the contract. We analyzed the educational provision based on the doctrine and also in the infra legal norms applicable to the contract. We have found that apprenticeship programs can include various courses and vocational education programs. We thus established a dialogue between labor legislation and educational legislation. We also analyzed some issues related to apprenticeship, such as the levels of education in Brazil, the historical duality between general education and vocational education, the age for school education and work, child labor and educational work provided for Child and Adolescent Statute (known in the original Portuguese as ECA). Finally, we briefly analyzed the transformation through which they went on apprenticeship based on the changes made according to The Consolidation of Labor Laws - CLL. under the Law 10,097 / 2000. apprenticeship becomes an instrument of public policy, which aims to achieve the right to work, professionalization and education targeted especially at adolescents between ages fourteen to eighteen and also for those people who are up to twenty-four years.

Keywords: Apprenticeship contract, Apprenticeship, Technical and vocational methodical training, Vocational Education and Training. 



\section{SUMÁRIO}

\section{INTRODUÇÃO 19 \\ CAPÍTULO 1. O contrato de aprendizagem como contrato especial de trabalho}

1.1. A aprendizagem e o contrato 23

1.2. O contrato de aprendizagem como contrato típico regulado pelo direito do trabalho.. 29

1.3. O conceito de contrato de aprendizagem .34

1.3.1. A idade para celebração do contrato de aprendizagem . .38

1.3.2. A obrigatória determinação do prazo ..... 40

1.4. Peculiaridades da disciplina legislativa do tipo ... .44

1.4.1. A obrigatoriedade de contratação: as "cotas" de aprendizagem. 44

1.4.2. A remuneração do aprendiz e o custeio da aprendizagem. .51

1.5. Tipo contratual e conteúdo formativo .55

1.6. A aprendizagem e outras relações de trabalho com prestações de formação profissional

1.6.1. O estágio: caracterização e distinções em relação à aprendizagem .59

1.7. A tipificação legislativa no Brasil e o seu contexto histórico. 61

\section{CAPÍTULO 2. O quid do contrato de aprendizagem: a formação técnico- profissional metódica}

2.1. O contrato de aprendizagem como parte de um projeto estatal de educação profissional

2.2. O conteúdo da prestação educacional do contrato de aprendizagem

2.3. Os programas de aprendizagem e a correspondência com os cursos (níveis) de educação profissional.

2.4. A Jurisprudência sobre a formação técnico-profissional metódica

2.5. As entidades qualificadas para o oferecimento da formação técnico-profissional metódica.

2.5.1. O Serviço Nacional de Aprendizagem Industrial - SENAI

2.5.2. Os demais Serviços Nacionais de Aprendizagem

2.5.3. A natureza jurídica dos Serviços Nacionais de Aprendizagem 

2.5.4. As novas entidades habilitadas à prestação da formação técnico-profissional em caráter complementar

Capítulo 3. $\mathrm{O}$ contrato de aprendizagem celebrado pelo adolescente: as tensões entre educação e profissionalização

3.1. Educação e profissionalização como direitos ........................................................... 125

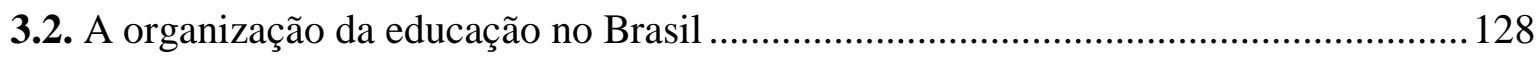

3.3. A dualidade educacional e seu reflexo nas disposições celetistas sobre a aprendizagem

3.3.1. Uma dualidade histórica e persistente 134

3.3.2. Experiências de articulação na história da educação brasileira 143

3.4. O trabalho infantil. A estipulação de uma idade mínima para a inserção no mundo do trabalho 146

3.5. A idade para a escola e a idade para o trabalho no ordenamento brasileiro 154

3.5.1. Trabalho artístico de crianças: flexibilização do abolicionismo?. 157

3.5.2. O trabalho educativo previsto no Estatuto da Criança e do Adolescente 166

\section{Capítulo 4. A aprendizagem brasileira no início do século XXI}

4.1. Lei $n^{\circ} 10.097 / 2000$ : uma nova aprendizagem para um novo tempo?.... 172

4.2. A aprendizagem como política pública 179

4.3. A ampliação quantitativa das relações de aprendizagem

CONCLUSÃO. 201

REFERÊNCIAS BIBLIOGRÁFICAS .209

\section{ANEXOS}

Decreto $\mathrm{n}^{\mathrm{o}}$ 9.579, de 22 de novembro de 2018 (arts. 43-75) ............................................223

Portaria do Ministério do Trabalho e Emprego - MTE nº 723 de 23 de abril 2012 233 



\section{INTRODUÇÃO}

A presente dissertação de mestrado tem por objeto o contrato de aprendizagem, com enfoque na análise de seus fundamentos, possibilidades e limites de pactuação. O referido contrato foi tipificado, no Brasil, na primeira metade do século $\mathrm{XX}$, no contexto da industrialização conduzida pelo Estado. Antes da tipificação, possuía, entre nós, uma restrita tipicidade social.

O primeiro capítulo é dedicado à análise da aprendizagem enquanto contrato de trabalho especial, o qual não se confunde com outros contratos de trabalho que possuem prestações educativas. Em regra, utilizamos o termo aprendizagem, em nosso trabalho, como sinônimo de contrato de aprendizagem, porque aquele é o nomen juris do contrato objeto do nosso estudo, e, ao menos na legislação laboral, o termo é utilizado sempre com o propósito específico de se referir a esse contrato.

Iniciamos a nossa análise com uma breve exposição histórica, que nos remete às origens do instituto, nas corporações de ofício medievais. Ainda neste capítulo, aduzimos sucintamente o contexto histórico em que ocorreu a tipificação em nosso ordenamento, com referências às primeiras normas sobre o tema.

A aprendizagem está prevista na Consolidação das Leis do Trabalho - CLT. A disciplina infralegal, nomeadamente o Decreto $n^{\circ}$ 9.579/2018 e a Portaria $n^{\circ} 723 / 2012$ do Ministério do Trabalho, também é analisada na medida em que contribui para a compreensão do instituto. Com base nesse arcabouço normativo fundamental, separamos alguns elementos que se prestam a caracterizar o tipo contratual de outros elementos que constituem meras peculiaridades resultantes da tipificação em nosso ordenamento.

O recurso à história e à legislação estrangeiras é parte desse esforço de definição dos elementos caracterizadores das relações de aprendizagem. Assim, utilizamo-nos da análise histórica e da análise de ordenamentos estrangeiros sem um propósito enciclopédico, mas apenas na medida em que foram necessárias ao atingimento do nosso objetivo.

O destaque à legislação francesa se deu por quatro motivos: o primeiro, de caráter subjetivo, é a competência linguística do pesquisador, a qual possibilitou uma análise mais aprofundada do ordenamento laboral francês (mais do que o enaltecimento de uma qualidade, trata-se do reconhecimento de uma limitação); o segundo é a constatação de que o contrato objeto de nossa pesquisa tem sido objeto de intenso debate na sociedade francesa, que adota uma perspectiva crítica e propositiva; o terceiro é o fato de que, não obstante tenha 
sofrido significativas alterações desde o seu surgimento e passado por períodos de declínio, a aprendizagem já era uma prática social bem desenvolvida naquele país antes mesmo da tipificação legislativa contemporânea; o quarto advém da constatação de que, na França, assim como Brasil, a aprendizagem é instrumento de uma política pública de inserção laboral.

No capítulo 2, analisamos a prestação educativa do contrato de aprendizagem. Dedicamos um capítulo a esse tema porque é a referida prestação que justifica a especialidade do contrato. O elemento educativo está na causa do contrato, que, como nos ensina a doutrina analisada, é a troca entre trabalho, remuneração e educação profissional. Consideramos que esse ponto mereceria, por si só, um estudo multidisciplinar aprofundado.

Cabe esclarecer que, em virtude do recorte temático de nossa pesquisa, analisamos o aspecto educativo do contrato na medida em que se mostrou útil para tentar definir, no contexto de expansão quantitativa das relações de aprendizagem, que ocorreu após o advento da Lei $n^{\circ} 10.097 / 2000$, as possibilidades e limites de pactuação e também para fornecer elementos para que o jurista possa examinar eventual inadimplemento relativo à prestação educativa. Para isso, interpretamos sistematicamente a legislação celetista e a legi slação que disciplina a educação profissional. Com esse mesmo intuito, selecionamos e analisamos algumas decisões proferidas por nossos tribunais.

A CLT utiliza o termo "formação técnico-profissional metódica" para se referir à prestação educativa do contrato de aprendizagem. Observamos que o termo, mesmo com a definição dada pela lei, não oferece ao intérprete uma exata compreensão sobre as possibilidades educacionais que os programas de aprendizagem comportam. Como aduziremos oportunamente em nosso trabalho, a expressão utilizada pela legislação celetista parece ser mais um registro das ideias que fundamentaram a tipificação da aprendizagem do que um comando legal. Assim, buscamos na disciplina infralegal da aprendizagem, bem como na legislação educacional, esclarecer os contornos da prestação educativa do contrato de aprendizagem.

Consideramos que a legislação celetista é muito sucinta na parte em que disciplina o conteúdo dos programas de aprendizagem. Essa constatação foi, inclusive, um "ponto de partida" de nossa pesquisa. Tratando-se de um contrato, é preciso que o jurista compreenda as obrigações que dele decorrem, ainda que tenham caráter educacional. Não foi preciso adentrar em doutrinas da educação para observar que a prestação educativa do contrato de aprendizagem, do mesmo modo que enseja múltiplas possibilidades de pactuação, também estabelece restrições à sua celebração. 
A brevidade da lei pode resultar em programas de aprendizagem mais completos e adaptados às necessidades das empresas e dos aprendizes, como também pode ser fonte de precarização das relações de aprendizagem. Assim, procuramos encontrar um patamar mínimo relativo à prestação educacional do contrato. $\mathrm{O}$ desrespeito a esse patamar mínimo, revelado por meio de uma interpretação sistemática entre a legislação trabalhista e a legislação educacional, implica a nulidade do contrato de aprendizagem, por se tratar de precarização da relação de trabalho.

No capítulo 3, analisamos alguns temas correlatos e caros à aprendizagem, que demonstram a complexidade dessas relações. São temas que se relacionam tanto à aprendizagem enquanto contrato - relação individual de trabalho entre empregador e aprendiz - como à aprendizagem enquanto política pública

A aprendizagem, desde a sua tipificação, no Brasil, foi destinada a adolescentes, não obstante a idade mínima ter variado, por meio de alterações legislativas e constitucionais, de modo que, na maior parte do tempo (como atualmente), abrangeu apenas parte desse período da vida, que, de acordo com o art. $2^{\circ}$ do ECA, começa aos doze anos.

A Lei $n^{\circ} 11.180 / 2005$ alterou o diploma celetista para ampliar o limite etário superior para além da adolescência. O Decreto $\mathrm{n}^{\circ}$ 9.579/2018, no entanto, em seu art. 53, caput, evidenciando o caráter de política pública da aprendizagem, estabelece que os adolescentes entre quatorze e dezoito anos têm prioridade na contratação. Ou seja, apesar de não ser mais restrita a adolescentes, a aprendizagem é prioritariamente destinada a esse grupo.

Assim, o aprendiz é preferencialmente um adolescente que concilia educação básica obrigatória (nono ano do ensino fundamental ou as séries do ensino médio), educação profissional - por meio do programa de aprendizagem - e trabalho. A CLT, nos dispositivos em que aborda esse ponto, o faz com uma perspectiva de compatibilização meramente temporal, buscando assegurar que, ao longo do dia ou da semana, o aprendiz tenha condições de cumprir tanto a carga horária escolar como a relativa ao programa de aprendizagem.

Com base nessa constatação, analisamos as relações entre a educação escolar e educação profissional. A doutrina da educação, como será exposto, aponta para a difícil relação entre educação e profissionalização, que se evidencia em uma histórica dualidade, atenuada nos últimos anos pela possibilidade de maior articulação (integração) entre a educação profissional técnica de nível médio e o ensino médio. Assim, ainda que não tenhamos um intuito propositivo (no âmbito de nossa pesquisa jurídica, preferimos deixar a busca de soluções para os pesquisadores da educação), procuramos evidenciar que entre a 
escola e os programas de aprendizagem (e a educação profissional, em geral) há tensões mais profundas do que a simples compatibilização temporal.

Considerando que o constituinte brasileiro excepcionou somente a aprendizagem da regra geral sobre a idade mínima para o trabalho, realizamos uma análise sistemática entre a idade para a educação escolar, a idade para o trabalho e o trabalho infantil, que é um tema intrinsecamente relacionado aos dois primeiros. $\mathrm{O}$ trabalho educativo previsto no ECA foi também analisado neste capítulo, porque o consideramos um método educativo e não propriamente um trabalho.

Por fim, no capítulo 4, buscamos analisar as transformações no instituto da aprendizagem após a edição da Lei ${ }^{\circ}$ 10.097/2000. Essa foi a primeira de uma série de leis que alteraram profundamente a disciplina jurídica da aprendizagem. Assim, ao longo do nosso trabalho, necessariamente, mencionamos as alterações promovidas por esses diplomas. No referido capítulo, entretanto, procuramos analisar aspectos que, embora sejam resultados das alterações legislativas, não estão expressamente previstos na legislação.

A aprendizagem, a partir dos anos 2000, passou a ser um instrumento de uma política pública de inclusão social e cidadania, por meio da inserção do jovem no mercado de trabalho e do oferecimento, nos programas de aprendizagem, de matérias que vão além da formação profissional. Esse aspecto é evidenciado pela disciplina infralegal do instituto. $\mathrm{O}$ Decreto $n^{\circ} 9.579 / 2018$ possui dispositivos especificamente destinados a jovens em situação de vulnerabilidade e a Portaria $\mathrm{n}^{\circ}$ 723/2012 do Ministério do Trabalho, em suas disposições sobre diretrizes (art. 10), evidencia que os programas de aprendizagem possuem objetivos muito mais amplos do que a mera preparação para o trabalho. Ainda que a nossa pesquisa não tenha como objetivo analisar a aprendizagem como política pública, entendemos que a análise dessa qualidade assumida pela aprendizagem foi importante para compreender as alterações legislativas supramencionadas.

No título de nosso trabalho fizemos alusão à "evolução do direito à educação", com o intuito de ressaltar que a nossa análise se pautou eminentemente na prestação educativa do contrato e nos assuntos a ela relacionados, quais sejam, o direito à educação e o seu conteúdo, que se revela por meio das leis que disciplinam a educação brasileira. A palavra evolução foi utilizada para se referir às transformações observadas ao longo do tempo, narradas em nosso trabalho. Procuramos, assim, aproximar o contrato de sua principal prestação, que o torna um contrato de trabalho especial para o direito do trabalho e muito especial para a vida de centenas de milhares de aprendizes. 


\section{CONCLUSÃO}

O Contrato de Aprendizagem é um contrato de trabalho especial, por meio do qual, em uma relação de emprego, o empregador se obriga a oferecer ao aprendiz uma prestação de educação profissional. Esse contrato não é uma criação legislativa; decorre de uma prática social que remonta às corporações de ofício, surgidas na Idade Média europeia. A industrialização conferiu novos contornos ao instituto, de modo que alguns doutrinadores se referem à aprendizagem contemporânea como "aprendizagem moderna".

Observamos, assim, que alguns elementos, ainda que tenham passado a integrar a disciplina legislativa do tipo - no Brasil e em outros ordenamentos estrangeiros analisados, nomeadamente o francês e o italiano -, decorrem da origem, como prática social, uma vez que são destinados à satisfação das necessidades dos aprendizes e seus empregadores. Esses elementos são a idade para a celebração do contrato e a determinação do prazo do contrato ou do período de aprendizagem, em ordenamentos que permitem a celebração de contrato de aprendizagem por tempo indeterminado.

O contrato de aprendizagem tem, no polo obreiro, uma pessoa jovem. Os ordenamentos jurídicos, de acordo com a evolução dos patamares de proteção à criança e ao adolescente, fixaram idades mínimas para pactuação. Sobre esse ponto, é pertinente rememorar as Convenções n ${ }^{\circ} 138$ e n⿳亠 182 da OIT, que objetivam a erradicação do trabalho infantil.

No Brasil, podem ser aprendizes pessoas entre quatorze e vinte e quatro anos, sendo que o atingimento da idade máxima é causa de extinção do contrato. Há que se considerar que, não obstante envolva prestações de educação profissional, a relação de aprendizagem é uma relação de trabalho. O aprendiz é um trabalhador que, já inserido em uma relação de emprego, recebe educação profissional. Ou seja, a pactuação de contrato de aprendizagem em idade inadequada pode ser tão prejudicial ao indivíduo quanto a pactuação de um contrato de trabalho comum.

A fixação, pelos ordenamentos, de uma idade máxima para celebração do contrato, por outro lado, é uma medida que evita a precarização das relações de trabalho, uma vez que, em tese, pessoas com mais idade já possuem conhecimentos e certificações suficientes que lhes possibilitam a inserção em relações comuns de emprego, com condições mais vantajosas. 
Concluímos, assim, que a questão etária, no contrato de aprendizagem, advém da sua causa, que é fundamentalmente a mesma desde a sua gênese, qual seja, o oferecimento de educação profissional, por meio de uma relação de trabalho, àqueles que estão no início de suas vidas profissionais - não necessariamente desempenhando o primeiro trabalho. Assim como o próprio contrato de aprendizagem, a análise histórica demonstrou que a estipulação da idade não é uma criação puramente legislativa, mas tem origem na "prática negocial", porque, a princípio, um idoso que busca desempenhar uma nova ocupação, por exemplo, poderia se beneficiar de uma relação de aprendizagem.

Assim como a idade mínima permitida para pactuação, a idade máxima também varia conforme o ordenamento no qual o contrato está tipificado. Concluímos que esses marcos etários são fixados pelos legisladores ao levarem em consideração uma multiplicidade de fatores, como a sofisticação nas bases técnicas da produção, que exigem profissionais com maior tempo de preparação, e as dificuldades que os jovens enfrentam para inserção no mercado de trabalho. Nesse sentido, há que se rememorar a lei francesa (Loi no 2018-771 du 5 septembre 2018) que, em 2018, alterou o Code du Travail para, a partir de $1^{\circ}$ de janeiro de 2019, permitir a celebração de contrato de aprendizagem por pessoas de até vinte e nove anos completos.

Do mesmo modo, a determinação do tempo contratual ou do período de aprendizagem - em ordenamentos em que é autorizada a pactuação do contrato de aprendizagem por tempo indeterminado -, além de ser uma disposição legal contra a precarização das relações de trabalho, também decorre da prática da aprendizagem, desde a sua gênese. Cabe rememorar a obra de Guinot, a qual observa que, ainda no tempo das corporações de ofício, os estatutos dessas corporações fixavam o período de aprendizagem necessário para tornar-se um "companheiro".

Por outro lado, analisando especificamente a legislação brasileira, concluímos que alguns elementos que compõem a disciplina do contrato de aprendizagem são peculiaridades decorrentes do contexto da tipificação e das posteriores alterações legislativas. Assim, não se prestam a caracterizar a aprendizagem como instituto juslaboral. É o caso, por exemplo, dos percentuais mínimo e máximo de contratação de aprendizes. A fixação de percentual máximo, raramente ultrapassado pelas empresas, tem o intuito de evitar a precarização das relações de trabalho. A estipulação de um percentual mínimo de contratação, aplicável aos "estabelecimentos de qualquer natureza" (art. 429, caput, CLT), evidencia o intuito do legislador de expansão quantitativa das relações de aprendizagem, compreendida como uma importante política pública. 
A prestação educativa é fundamental para a relação de aprendizagem e justifica a especialidade do contrato. A importância se extrai do próprio texto constitucional, pois a aprendizagem é a única exceção, estabelecida pelo constituinte, à idade mínima de dezesseis anos para o trabalho, além contribuir para a concreção de direitos fundamentais, como o direito ao trabalho e o direito à profissionalização.

A CLT utiliza o termo "formação técnico-profissional metódica" quando se refere à prestação educacional da relação de aprendizagem (art. 428, caput). A interpretação autêntica (art. $428, \S 4^{\circ}$ ) não é muito clara sobre as possibilidades e os limites de pactuação do contrato de aprendizagem, à luz de sua prestação educativa. Ademais, a definição legal parece ser mais um registro das origens da aprendizagem no Brasil, orientada pela doutrina de racionalização do trabalho de Taylor, do que um comando para a prestação de um modo ou nível específico de educação profissional.

Os adjetivos "metódico" e "progressivo", assim como o uso da palavra "tarefa", parecem ser uma evocação saudosa das "séries metódicas de ofício", assim como da obra de Taylor, que defendia a implementação do sistema de "administração das tarefas" ("administração científica") para obtenção do "máximo de prosperidade". Nesse sistema, cabia ao trabalhador receber as tarefas, "cientificamente" preparadas pela direção, e executálas no tempo adequado.

Assim, considerando também que a legislação brasileira é sucinta no que se refere ao conteúdo da prestação educativa do contrato de aprendizagem, nos afastamos um pouco dessas definições e buscamos, com base na disciplina infralegal e na doutrina, melhor precisar o que a referida prestação comporta. A investigação é eminentemente jurídica, uma vez que objetiva encontrar fundamentos para aferir não só as possibilidades e limites de pactuação do contrato como também eventual inadimplemento da obrigação de oferecer a prestação educativa avençada.

Constatamos que a aprendizagem ainda está intrinsecamente relacionada à preparação para o desempenho de, no mínimo, uma ocupação descrita na Classificação Brasileira de Ocupações. A ocupação deve, no entanto, requerer, para seu exercício, curso ou programa de educação profissional. Trata-se de um patamar mínimo para evitar a precarização das relações de aprendizagem.

A aprendizagem, no entanto, não é um "nível" de ensino, mas comporta múltiplos níveis de educação profissional. A partir da doutrina da educação, arriscamos afirmar que a aprendizagem (rectius a prestação educacional do contrato de aprendizagem ou o programa de aprendizagem) é um modo por meio do qual a educação profissional pode ser oferecida, 
em diferentes níveis. Evitamos, assim, associar a aprendizagem ao termo "formação inicial". O fato de ser pactuada entre empresa e uma pessoa jovem não limita a aprendizagem ao nível de formação inicial. Na França, por exemplo, há programas de aprendizagem de nível superior, e expressivo número de Centros de formação de aprendizes (Centres de formation d'apprentis - CFA) oferecem programas nesse nível.

No Brasil, a disciplina infralegal do tipo limitou os programas de aprendizagem aos níveis de "formação inicial e continuada" e "técnico médio". O Decreto no 5.154/2004 não utiliza o termo "nível", mas sim a expressão "cursos e programas de [...]", ao contrário do decreto anterior já revogado. Porém, por uma questão didática e porque o próprio decreto e documentos oficiais sobre a aprendizagem não abandonaram completamente o uso do termo, mantivemos o seu uso.

Consideramos, assim, que, como patamar mínimo de proteção ao aprendiz, deve lhe ser assegurado ao menos programa de aprendizagem de nível "qualificação profissional ou formação inicial e continuada" (o nível mais básico da educação profissional brasileira), que lhe possibilite o exercício de uma ocupação descrita na Classificação Brasileira de Ocupações. Nossa conclusão decorre da análise da disciplina infralegal da aprendizagem, principalmente da Portaria $n^{\circ} 723 / 2012$ do Ministério do Trabalho e do Decreto $n^{\circ}$ 9.579/2018, assim como de documentos oficiais sobre a aprendizagem, como o CONAP Catálogo Nacional de Programas de Aprendizagem, previsto no art. $8^{\circ}$ da referida portaria.

A CLT, em vez de expressamente estabelecer uma correspondência com a legislação educacional, se valeu da expressão "formação técnico-profissional metódica" que, como observamos, fornece ao intérprete os contornos básicos da prestação educacional, mas carece de precisão que assegure ao aprendiz um patamar mínimo de proteção contra a precarização das relações de aprendizagem.

$\mathrm{O}$ direito do trabalho tem como objetivo o estabelecimento desses patamares mínimos de proteção. Assim, é pertinente uma disciplina mais aprofundada, na própria CLT, sobre a prestação educativa do contrato de aprendizagem. O legislador poderia, inclusive, criar, dentro do tipo geral, subtipos de aprendizagem relacionados ao conteúdo da prestação educativa, para melhor disciplinar e proteger as relações de aprendizagem.

A análise realizada no Capítulo 3 nos conduz a uma conclusão sistemática entre educação, educação profissional, profissionalização e aprendizagem. Naquele capítulo, procuramos, em apertada síntese, aduzir a evolução da educação brasileira dos tempos da tipificação legislativa da aprendizagem até os tempos recentes. Mesmo após o advento da Constituição de 1988, observamos expressivos avanços no que se refere à educação. 204 
Atualmente, a educação básica - que compreende a educação infantil, o ensino fundamental e o ensino médio - é obrigatória. O dever do Estado de promover "progressiva universalização do ensino médio gratuito" a nosso ver está superado pelo dever de garantir a todos educação básica gratuita, inclusive o ensino médio. Ademais, a Lei de Diretrizes e Bases da Educação Nacional (arts. 36-B e 36-C) prevê que a educação profissional técnica de nível médio pode ser desenvolvida de forma articulada ao ensino médio (integrada ou concomitante) ou de forma subsequente, para as pessoas que já concluíram o ensino médio. Busca-se, assim, amenizar a histórica dualidade entre educação propedêutica (para o ensino superior) e educação profissional.

Essa evolução deve ser considerada também na interpretação da disciplina legislativa da aprendizagem. A "formação técnico-profissional metódica" não pode ser interpretada como "formação inicial" para rápido ingresso de jovens no mercado de trabalho. Não obstante os notórios problemas de qualidade da educação pública brasileira e a distorção idade-série que afeta expressivo percentual dos alunos, há que se considerar que o aprendiz é, preferencialmente, por disposição infralegal, um adolescente que está terminando o ensino fundamental (nono ano) ou cursando o ensino médio. Assim, a lei deve assegurar não apenas a simples expansão das relações de aprendizagem como também a expansão de programas de aprendizagem de nível técnico médio, compatíveis, assim, com a educação previamente recebida pelo aprendiz.

Outrossim, há que se mencionar a dimensão de política pública que a aprendizagem assumiu, sobretudo a partir das alterações promovidas na CLT pela Lei no 10.097/2000. Consideramos que a análise - ainda que breve, dado os limites de nossa pesquisa - desse aspecto foi importante para compreender as últimas alterações substanciais na disciplina legislativa do tipo.

A aprendizagem, como instrumento de uma política pública, contribui para a concreção de direitos fundamentais, como o direito à profissionalização e o direito ao trabalho. Em virtude da importância que a educação e o trabalho possuem para o desenvolvimento da pessoa, a aprendizagem não se limita ao aspecto laboral, constituindo uma política pública de inclusão social e cidadania. Assim, embora não tenhamos analisado o conteúdo dos programas oferecidos, constata-se que esse aspecto de política pública influenciou os programas de aprendizagem, que não se limitam à mera preparação para o desempenho de uma ocupação, oferecendo aos aprendizes conteúdos relevantes para o seu integral desenvolvimento como pessoa humana. 
A Constituição Federal estabelece, no art. 227, que o Estado, a sociedade e a família devem assegurar à criança, ao adolescente e ao jovem, com "absoluta prioridade", entre outros direitos, o direito à educação e o direito à profissionalização. No artigo $6^{\circ}$, caput, do referido diploma, o direito ao trabalho é elevado ao status de direito fundamental. Os notórios entraves que os jovens enfrentam para ingresso no mundo do trabalho constituem um verdadeiro problema público e, ademais, como observamos em nossa pesquisa, a profissionalização do jovem é, em si, um problema, considerando a dualidade educacional e as exigências empresariais, que se complexificam com as alterações nas bases técnicas da produção.

Portanto, é absolutamente legítimo que o Estado se valha da aprendizagem como instrumento para concreção de direitos e solução de problemas enfrentados por grande parte dos jovens. Por outro lado, a responsabilidade empresarial, materializada sobretudo na obrigação de contratar aprendizes e na contribuição compulsória aos Serviços Nacionais de Aprendizagem, decorre primeiramente do dever constitucional de toda a sociedade de contribuir para a profissionalização dos jovens e, outrossim, da função social da propriedade, prevista no art. $5^{\circ}$, XXIII, da Constituição Federal. Há que se considerar também que o jovem, quando busca a educação profissional, o faz muitas vezes com o intuito de atender às exigências empresariais; portanto, nada mais justo que as empresas também participem no custeio de programas e cursos destinados à preparação para o trabalho.

Cabe observar, no entanto, que os objetivos da aprendizagem enquanto política pública não podem se sobrepor à sua causa jurídica, sob pena de desvirtuamento e precarização da relação. Assim, o caráter propriamente educativo, materializado na prestação de educação profissional, deve manter a sua centralidade, ainda que a aprendizagem, coletivamente, atenda a finalidades mais amplas. Portanto, ao aprendiz deve ser garantida uma verdadeira inserção na estrutura da empresa, por meio de uma relação de emprego e recebimento de educação profissional, nos termos previstos pela legislação educacional. Ademais, a aprendizagem deve ter como objetivo a preparação para ocupações que, de fato, exijam preparação para o seu desempenho, uma vez que não é "obra social" de empresa, nem instrumento de caridade de pessoas bem-intencionadas.

Não podemos, assim, retornar aos primórdios do ensino de ofícios no Brasil, quando esse tipo de educação, por ideias preconceituosas, era um instrumento precário destinado aos jovens pobres para que estes não caíssem nas supostas tentações decorrentes de sua condição social. 
Do mesmo modo que o trabalho informal - que neste momento de nossa história traz um alívio temporário para milhões de brasileiros - não é tolerado pelo direito do trabalho, a aprendizagem precária, isto é, aquela que não objetiva verdadeira educação profissional, não pode ser admitida por nosso direito, nem mesmo por supostos benefícios decorrentes da imediata inserção do jovem em uma relação laboral. A aprendizagem precária não beneficia o jovem trabalhador, mas apenas aqueles que, obrigados a contratar e oferecer educação profissional, buscam se desincumbir pelos modos mais fáceis e baratos. 


\section{REFERÊNCIAS BIBLIOGRÁFICAS}

ANTUNES, Ricardo. Adeus ao trabalho?: ensaio sobre as metamorfoses e a centralidade do mundo do trabalho. 16. ed. São Paulo: Cortez, 2015.

ARAT, Zehra F. Kabasakal. Analyzing Child Labor as a Human Rights Issue: Its Causes, Aggravating Policies, and Alternative Proposals. Human Rights Quarterly, v. 24, n. 1, feb./2002.

Disponível

em:

https://www.jstor.org/stable/20069593?seq=1\#page_scan_tab_contents.

ARAÚJO, Ronaldo Marcos de Lima. Instituições de formação profissional - história e perspectivas: o projeto da nova institucionalidade da educação profissional brasileira dos anos 1990. Ensaio: avaliação e políticas públicas em educação, Rio de Janeiro, v. 22, n. $82,2014$.

AUDI, Amanda. Senai, que forma jovens aprendizes, faz lobby secreto para acabar com programa de aprendizes. The Intercept_Brasil, 15 ago. 2018. Disponível em: https://theintercept.com/2018/08/15/cni-acabar-aprendizes/.

AUGUSTO, Maria Helena Oliva. Políticas públicas, políticas sociais e políticas de saúde: algumas questões para reflexão e debate. Tempo Social, São Paulo, v. 1, n. 2, dez. 1989. Disponível em: http://www.scielo.br/scielo.php?script=sci_arttext\&pid=S0103$20701989000200105 \& \operatorname{lng}=$ en\&nrm $=$ iso.

AUZERO, Gilles; BAUGARD, Dirk; DOCKES, Emmanuel. Droit du travail. 31. ed. Paris: Dalloz, 2017.

BIANCA, Cristina Corrêa. A educação infantil. In: OLIVEIRA, Romualdo P. de; ADRIÃO, Theresa. Organização do ensino no Brasil - níveis e modalidades na Constituição Federal e na LDB. São Paulo: Xamã, 2007.

BLEY, Regina Bergamaschi. Programa aprendiz: a contribuição do Estado do Paraná no desenvolvimento de políticas públicas voltadas para a profissionalização e inclusão social de adolescentes e jovens. In: JOSVIAK, Mariane; BLEY, Regina Bergamaschi (Orgs.). Ser Aprendiz!: aprendizagem profissional e políticas públicas - aspectos jurídicos, teóricos e práticos. São Paulo: LTr, 2009. 
BONNET, Michel; SCHLEMMER, Bernard. Aperçus sur le travail des enfants. Mondes en développement, 2009/2 ( $\mathrm{n}^{\circ}$ 146), p. 11-25. Disponível em: https://www.cairn.info/revuemondes-en-developpement-2009-2.htm-page-11.htm.

BRASIL. Ministério da Educação. Parecer CNE/CEB No: 11/2012. Disponível em: http://portal.mec.gov.br/index.php?option=com_docman\&view=download\&alias=10804pceb011-12-pdf\&Itemid=30192.

BRASIL. Ministério do Trabalho e Emprego. Catálogo Nacional de Programas de Aprendizagem Profissional - CONAP. Disponível em: http://trabalho.gov.br/images/Documentos/Aprendizagem/conap-em-edicao-out-2008.pdf.

BRASIL. Ministério do Trabalho. Classificação Brasileira de Ocupações - CBO. Disponível em: http://www.mtecbo.gov.br/cbosite/pages/informacoesGerais.jsf.

BRASIL. Ministério do Trabalho e Emprego. Manual da aprendizagem, 2014. Disponível em:http://www.trabalho.gov.br/images/Documentos/Aprendizagem/Manual_da_Aprendiza gem2017.pdf.

BRASIL. Ministério do Trabalho. Secretaria de Políticas Públicas de Emprego. Boletim da Aprendizagem Profissional - jan. a dez. 2017. Disponível em: http://trabalho.gov.br/images/Documentos/Aprendizagem/Boletim_jan_a_dez_2017.pdf.

BRISCIANI, Massimo; TRIZIO, Marcella de. L'apprendistato e lo stage. Milão: Giuffrè, 2016.

CAGGIANO, Monica Herman Salem. A educação, direito fundamental. In: Direito à educação - Aspectos constitucionais. Coord. Nina Beatriz Stocco Ranieri. Org. Sabine Righetti. São Paulo: Edusp, 2009.

CARVAlHO, Marcelo Augusto Monteiro de. A criação do SENAI no contexto da Era Vargas. Curitiba: Prismas, 2015.

CORSEUIL, Gustavo Henrique; FOGUEL, Miguel; GONZAGA, Gustavo. A aprendizagem e a inserção de jovens no mercado de trabalho: uma análise com base na Rais. Brasília, $2016 . \quad$ IPEA, Disponível em: http://repositorio.ipea.gov.br/bitstream/11058/7404/1/RP_Aprendizagem_2016.pdf. 
CUNHA, Luiz Antônio. O ensino de ofícios nos primórdios da industrialização. São Paulo/Brasília: Unesp/Flacso, 2000.

CUNHA, Luiz Antônio. O ensino profissional na irradiação do industrialismo. São Paulo/Brasília: Unesp/Flacso, 2005.

DELAUTRE, Guillaume, Le modèle dual allemand: Caractéristiques et évolutions de l'apprentissage em Allemagne, Document d'études, n. 185, set. 2014. Disponível em: https://dares.travail-emploi.gouv.fr/dares-etudes-et-statistiques/etudes-etsyntheses/document-d-etudes/article/le-modele-dual-allemand.

DI PIETRO, Maria Sylvia Zanella. Direito administrativo. 28. ed. São Paulo, Atlas, 2015. FERRETTI, Celso João. As mudanças no mundo do trabalho e a qualidade da educação. In: WERNER, Market (Org.). Trabalho, qualificação e politecnia. Campinas: Papirus, 1996. FOHLEN, Claude. Révolution industrielle et travail des enfants. Annales de démographie historique, 1973, p. 319-325. Disponível em: https://www.persee.fr/doc/adh_00662062_1973_num_1973_1_1199.

FONSECA, Ricardo Tadeu Marques da. O direito à profissionalização: da teoria à prática. In: JOSVIAK, Mariane; BLEY, Regina Bergamaschi (Orgs.). Ser Aprendiz!: aprendizagem profissional e políticas públicas - aspectos jurídicos, teóricos e práticos. São Paulo : LTr, 2009.

FRANÇA (FRANCE). Rapport pour le développement de l'apprentissage: Synthèse de la concertation, janvier 2018. Disponível em: https://www.strategie.gouv.fr/sites/strategie.gouv.fr/files/atoms/files/rapport-concertationapprentissage-30-01-2018.pdf.

FRIGOTTO, Gaudêncio. A relação da educação profissional e tecnológica com a universalização da educação básica. In: I CONFERÊNCIA NACIONAL DE EDUCAÇÃo Profissional e TecnolóGica, Anais [...], Brasília, Ministério da Educação, Secretaria de Educação Profissional Tecnológica, 2007.

GONÇALVES, Ana Lucia de Alencastro. Aprendizagem profissional: trabalho e desenvolvimento social e econômico, Estud. Av. [online], 2014, v. 28, n. 81. Disponível em:http://www.scielo.br/scielo.php?script=sci_arttext\&pid=S010340142014000200013\&l $\mathrm{ng}=\mathrm{en} \& \mathrm{nrm}=$ iso. 
GOUVEIA, Maria Cristina Soares de. Tempos de aprender -A produção histórica da idade escolar. Revista Brasileira de História da Educação, v. 4, n. 2 [8], 2004. Disponível em: http://www.periodicos.uem.br/ojs/index.php/rbhe/article/view/38690.

GUINOT, Jean-Pierre. Formation professionnelle et travailleurs qualifiés depuis 1979. Paris: Domat-Montcherestien, 1946.

JOSVIAK, Mariane. Políticas públicas e aprendizagem: a participação do Ministério Público do Trabalho na construção de políticas públicas para profissionalizar jovens no Paraná. In: JOSVIAK, Mariane; BLEY, Regina Bergamaschi (Orgs.). Ser Aprendiz!: aprendizagem profissional e políticas públicas - aspectos jurídicos, teóricos e práticos. São Paulo: LTr, 2009.

KOIKE, Beth. Escolas questionam o Sistema S. Valor Econômico, 19 julho 2018, versão on-line. Disponível em: https://www.valor.com.br/empresas/5669595/escolas-questionamsistema-s.

KUENZER, Acácia Zeneida. Pedagogia da fábrica - As relações de produção e a educação do trabalhador. 4. ed. São Paulo: Cortez, 1995.

LA HOVARY, Claire. Le droits fondamentaux au travail. Genebra: Graduate Institute Publications, 2009. Disponível em: https://books.openedition.org/iheid/979.

LIBÂNEO, José Carlos; OLIVEIRA, João Ferreira de; TOSCHI, Mirza Seabra. Educação escolar: políticas, estrutura e organização. São Paulo: Cortez, 2012.

LOPES, Alpiniano do Prado. SILVA, Audaliphal Hildebrando da. JOSVIAK, Mariane. MARQUES, Rafael Dias. A aprendizagem na administração pública. In: JOSVIAK, Mariane e BLEY, Regina Bergamaschi (Orgs.). Ser Aprendiz!: aprendizagem profissional e políticas públicas: aspectos jurídicos, teóricos e práticos, São Paulo: LTr, 2009.

MANFREDI, Silvia Maria. Educação profissional no Brasil. São Paulo: Cortez, 2002.

MANFREDI, Silvia Maria. Trabalho, qualificação e competência profissional - das dimensões conceituais e políticas, Educação \& Sociedade, Campinas, 1999, v. 19, n. 64. Disponível em: http://www.scielo.br/scielo.php?script=sci_arttext\&pid=S0101$73301998000300002 \& \operatorname{lng}=\mathrm{en} \& \mathrm{nrm}=\mathrm{iso}>$.

ISSN $0101-$ 7330. http://dx.doi.org/10.1590/S0101-73301998000300002. 
MARQUES, Rafael Dias. Trabalho infantil artístico: possibilidades e limites. Rev. TST, Brasília, v. 79, n. 1, jan./mar. 2013. Disponível em: https://juslaboris.tst.jus.br/bitstream/handle/20.500.12178/38664/018_marques.pdf?sequen $\mathrm{ce}=1$.

MARTINOT, Bertrand. L'apprentissage, un vaccin contre le chômage des jeunes: plan d'action pour la France tiré de la réussite allemand. Institut Montaigne, maio de 2015. Disponível em: https://www.institutmontaigne.org/ressources/pdfs/publications/etude_apprentissage.pdf MARTINS, Adalberto. A proteção constitucional ao trabalho de crianças e adolescentes. São Paulo: LTr, 2002.

MARTINS, Ana Luíza Leitão. O trabalho artístico da criança e do adolescente. Dissertação de Mestrado. 2013. Faculdade de Direito da Universidade de São Paulo. São Paulo. Orientador: Oris de Oliveira, São Paulo.

MARTINS, Sérgio Pinto. Aprendiz em condomínio. Carta Forense, 02 dez. 2014. Disponível em: http://www.cartaforense.com.br/conteudo/colunas/aprendiz-emcondominio/14755

MAZZOTTA, Oronzo. Diritto del lavoro. 2. ed. Milão: Giuffrè, 2005.

MINHARRO, Erotilde Ribeiro dos Santos. A criança e o adolescente no direito do trabalho. São Paulo: LTr, 2003.

MORAES, Carmen Sylvia Vidigal. Ações empresariais e formação profissional - Serviço Nacional de Aprendizagem Industrial. São Paulo em perspectiva, São Paulo, v. 14, n. 2, abr.-jun. 2000.

OLIVEIRA, Adriel Rodrigues de. Início de carreira organizacional: um estudo dos programas de "trainees" das empresas privadas brasileiras, Tese de Doutorado. 1996. FEA-USP (Faculdade de Economia, Administração e Contabilidade da Universidade de São Paulo). Orientador: Prof. Dr. Antônio César Amaru Maximiano, São Paulo.

OLIVEIRA, Oris de. Trabalho e profissionalização do adolescente. São Paulo: LTr, 2009. OLIVEIRA, Romualdo P. de; ADRIÃO, Theresa. O ensino fundamental. In: Organização do ensino no Brasil - níveis e modalidades na Constituição Federal e na LDB. São Paulo: Xamã, 2007. 
ORGANIZAÇÃO INTERNACIONAL DO TRABALHO (OIT). Un avenir sans travail des enfants. Rapport global en vertu du suivi de la Déclaration de l'OIT relative aux principes et droits fondamentaux au travail. Rapport du Directeur Général, Genebra, Bureau International du Travail (Escritório Internacional do Trabalho), 2002. Disponível em: $\quad$ https://www.ilo.org/global/publications/ilo-bookstore/orderonline/books/WCMS_099156/lang--fr/index.htm

ORGANIZAÇÃO INTERNACIONAL DO TRABALHO (OIT). Convenções. Disponível em: https://www.ilo.org/brasilia/convencoes/lang--pt/index.htm.

ORGANIZAÇÃO INTERNACIONAL DO TRABALHO (OIT). Every Child Counts New Global Estimates on Child Labour. Genebra, 2002. Disponível em: https://www.ilo.org/ipec/Informationresources/WCMS_IPEC_PUB_742/lang-en/index.htm

ORGANIZAÇÃO INTERNACIONAL DO TRABALHO (OIT). O fim do trabalho infantil: um objetivo ao nosso alcance. Relatório global no quadro do seguimento da Declaração da OIT sobre os princípios e direitos fundamentais no trabalho. Brasília, Escritório da OIT no Brasil, 2006. Disponível em: https://www.ilo.org/brasilia/publicacoes/WCMS_233639/lang--pt/index.htm

PILETTI, Claudino; PILETTI, Nelson. História da educação de Confúcio a Paulo Freire. São Paulo: Contexto, 2011.

PINTO, José Marcelino de Rezende. O ensino médio. In: OLIVEIRA, Romualdo P. de; ADRIÃO, Theresa. Organização do ensino no Brasil - níveis e modalidades na Constituição Federal e na LDB. São Paulo: Xamã, 2007.

POWELL, Andrew. Apprenticeships Policy in England. Briefing paper, number CBP 03052, 29 June 2017.2 Disponível http://researchbriefings.files.parliament.uk/documents/SN03052/SN03052.pdf.

PROVENZI, Thaís Ellen Gomes. Programa de aprendizagem no setor público: um relato de experiência. In: JOSVIAK, Mariane, BLEY, Regina Bergamaschi e TRAUCZYNSKI, Silvia Cristina (Orgs.). Aprendizagem profissional e direitos humanos. São Paulo: LTr, 2017.

PUNTA, Riccardo Del. Diritto del lavoro. Milão: Giuffrè, 2017. 
RAMOS, Marise Nogueira. Ensino médio integrado: ciência, trabalho e cultura na relação entre educação profissional e educação básica. In: MOLL, Jaqueline et. al. Educação profissional e tecnológica no Brasil contemporâneo: desafios, tensões e possibilidades. Porto Alegre: Artmed, 2010.

RANIERI, Nina Beatriz Stocco. Os Estados e o direito à educação na Constituição de 1988: comentários acerca da jurisprudência do Supremo Tribunal Federal. In: Direito à educação - Aspectos constitucionais. Coord. Nina Beatriz Stocco Ranieri. Org. Sabine Righetti. São Paulo: Edusp, 2009.

SANTOS, Enoque Ribeiros dos. Da obrigatoriedade de contratação de aprendizes pela administração pública, sob uma hermenêutica constitucional. In: JOSVIAK, Mariane e BLEY, Regina Bergamaschi (Orgs.). Ser Aprendiz!: aprendizagem profissional e políticas públicas: aspectos jurídicos, teóricos e práticos. São Paulo: LTr, 2009.

SCHLEMMER, Bernard. Le "travail des enfants", étapes et avatars dans la construction d'un objet. In: SIROTA, Régine (Org.). Eléments pour une sociologie de l'enfance. Rennes : Presses universitaires de Rennes, 2006.

SCHLEMMER, Bernard. Le BIT, la mesure du "travail des enfants" et la question de la scolarisation. Cahiers de la recherche sur l'éducation et les savoirs, 2005. Disponível em: http://journals.openedition.org/cres/1978.

SECCHI, Leonardo. Políticas públicas: conceitos, esquemas de análise, casos práticos. São Paulo: Cengage Learning, 2011.

SECCO, Marco Antonio Areias; BIALLI, Lúcia Burzynski. A aprendizagem industrial básica e o SENAI Paraná: fazendo história na história dos jovens aprendizes. In: JOSVIAK, Mariane; BLEY, Regina Bergamaschi; TRAUCZYNSKI, Silvia Cristina (Orgs.). Aprendizagem profissional e direitos humanos: o direito fundamental dos jovens à profissionalização. São Paulo: Ltr, 2017.

SELVA, Simone; MICHEL, Maristela de Andrade; STRAPASSON, Marise Helena Johnson. Programa de Aprendizagem Profissional: a experiência da Associação de Educação Familiar e Social do Paraná. In: JOSVIAK, Mariane; BLEY, Regina Bergamaschi (Orgs.). Ser Aprendiz!: aprendizagem profissional e políticas públicas - aspectos jurídicos, teóricos e práticos. São Paulo: LTr, 2009. 
SENAC. Programa Senac de Aprendizagem. Disponível em: http://www.sp.senac.br/jsp/default.jsp?template=2378.dwt\&pag=aprendizagem.

SENAI. Serviço Nacional de Aprendizagem Industrial. Departamento Nacional. Metodologia SENAI de educação profissional. Brasília, SENAI DN, 2013. Disponível em: https://www.oitcinterfor.org/sites/default/files/file_publicacion/MSEP_Documento.pdf

SENAI. Serviço Nacional de Aprendizagem Industrial. Aprendizagem industrial. Manual de orientações às empresas. 5. ed. São Paulo, 2018. Disponível em: http://www.sp.senai.br/cursos/7/aprendizagem-industrial?menu=30.

SOUZA, Celina. Estado da arte da pesquisa em políticas públicas. In: HOCHMAN, Gilberto; ARRETCHE, Marta; MARQUES, Eduardo. (Orgs.) Políticas públicas no Brasil. Rio de Janeiro: Fiocruz, 2007.

SUSS, Marcia Aparecida Osovski. A aprendizagem e seus efeitos sobre a promoção social de adolescentes e jovens na história do trabalho infantil. In: JOSVIAK, Mariane; BLEY, Regina Bergamaschi (Orgs.). Ser Aprendiz!: aprendizagem profissional e políticas públicas - aspectos jurídicos, teóricos e práticos. São Paulo: LTr, 2009.

TAYLOR, Frederick Winslow. Princípios de administração científica. Trad. Arlindo Vieira Ramos. 8. ed. 14. reimpr. São Paulo: Atlas, 2009.

TEYSSIÉ, Bernard. Droit du Travail: 1. Relations individuelles de travail. 2.ed. Paris: Litec, 1992.

UNESCO. Glossário de Terminologia Curricular. Trad. Rita Brossard.Brasília, 2016. Disponível em: https://unesdoc.unesco.org/ark:/48223/pf0000223059

VASCONCELOS, Pedro Pais de. Contratos atípicos. Coimbra: Almedina, 1995.

VELOSO, José Rodrigo Paprotzki. Aprendizagem: metamorfose de uma política pública de educação e trabalho dirigida à juventude brasileira. Dissertação (Mestrado em Políticas Públicas). 2015. Escola de Artes, Ciências e Humanidades, USP, São Paulo. Orientador: Marta Maria Assumpção Rodrigues. Disponível em: http://www.teses.usp.br/teses/disponiveis/100/100138/tde-23052015-112340/pt-br.php

WEINSTEIN, Barbara. (Re)Formação da classe trabalhadora no Brasil (1920-1964). Trad. Luciano Vieira Machado. São Paulo: Cortez, 2000. 


\section{Legislação consultada:}

BRASIL. Consolidação das Leis do Trabalho. Disponível em: http://www.planalto.gov.br/ccivil_03/decreto-lei/Del5452.htm

BRASIL. Constituição dos Estados Unidos do Brasil de 1937. Disponível em: http://www.planalto.gov.br/ccivil_03/Constituicao/Constituicao37.htm

BRASIL. Constituição Federal de 1988. Disponível em: http://www.planalto.gov.br/ccivil_03/Constituicao/Constituicao.htm

BRASIL. Decreto $\mathrm{n}^{\mathrm{o}} 10.009$, de 26 de outubro de 1942. Disponível em: http://www.planalto.gov.br/ccivil_03/decreto/1930-1949/D10009.htm

BRASIL. Decreto $\mathrm{n}^{\mathrm{o}}$ 2.208, de 17 de abril de 1997. Disponível em: http://www.planalto.gov.br/ccivil_03/decreto/D2208.htm

BRASIL. Decreto $\mathrm{n}^{\mathrm{o}}$ 31.546, de 6 de outubro de 1952. Disponível em: http://www.planalto.gov.br/ccivil_03/decreto/1950-1969/D31546.htm

BRASIL. Decreto $\mathrm{n}^{\mathrm{o}}$ 494, de 10 de janeiro de 1962. Disponível em: http://www.planalto.gov.br/ccivil_03/decreto/historicos/dcm/dcm494.htm

BRASIL. Decreto $\mathrm{n}^{\mathrm{o}}$ 5.154, de 23 de julho de 2004 Disponível em: http://www.planalto.gov.br/ccivil_03/_Ato2004-2006/2004/Decreto/D5154.htm

BRASIL. Decreto $\mathrm{n}^{\circ}$ 5.598, de $1^{\circ}$ de dezembro de 2005 Disponível em: http://www.planalto.gov.br/ccivil_03/_ato2004-2006/2005/decreto/d5598.htm

BRASIL. Decreto $\mathrm{n}^{\mathrm{o}}$ 6.029, de 26 de julho 1940 Disponível em: http://www2.camara.leg.br/legin/fed/decret/1940-1949/decreto-6029-26-julho-1940324447-publicacaooriginal-1-pe.html

BRASIL. Decreto $\mathrm{n}^{\mathrm{o}}$ 6.029, de 26 de julho de 1940. Disponível em: http://www2.camara.leg.br/legin/fed/decret/1940-1949/decreto-6029-26-julho-1940324447-publicacaooriginal-1-pe.html

BRASIL. Decreto $\mathrm{n}^{\mathrm{o}}$ 6.141, de 28 de dezembro de 1943. Disponível em: http://www.planalto.gov.br/ccivil_03/decreto-lei/1937-1946/Del6141.htm 
BRASIL. Decreto $\mathrm{n}^{\mathrm{o}}$ 6.633, de 5 de novembro de 2008. Disponível em: http://www.planalto.gov.br/ccivil_03/_Ato2007-2010/2008/Decreto/D6633.htm

BRASIL. Decreto $\mathrm{n}^{\circ}$ 6.635, de 5 de novembro de 2008. Disponível em: http://www.planalto.gov.br/ccivil_03/_Ato2007-2010/2008/Decreto/D6635.htm

BRASIL. Decreto $\mathrm{n}^{\mathrm{o}}$ 6.481, de 12 de junho de 2008. Disponível em: http://www.planalto.gov.br/ccivil_03/_ato2007-2010/2008/decreto/d6481.htm

BRASIL. Decreto $\mathrm{n}^{\mathrm{o}}$ 7.566, de 23 de setembro de 1909. Disponível em: http://www2.camara.leg.br/legin/fed/decret/1900-1909/decreto-7566-23-setembro-1909525411-norma-pe.html

BRASIL. Decreto $\mathrm{n}^{\mathrm{o}}$ 9.579, de 22 de novembro de 2018. Disponível em: http://www.planalto.gov.br/ccivil_03/_Ato2015-2018/2018/Decreto/D9579.htm

BRASIL. Decreto-lei $\mathrm{n}^{\mathrm{o}}$ 1.238, de 2 de maio de 1939. Disponível em: http://www2.camara.leg.br/legin/fed/declei/1930-1939/decreto-lei-1238-2-maio-1939349345-publicacaooriginal-1-pe.html

BRASIL. Decreto-lei $\mathrm{n}^{\circ}$ 4.048, de 22 de janeiro de 1942. Disponível em: http://www.planalto.gov.br/ccivil_03/decreto-lei/1937-1946/Del4048.htm

BRASIL. Decreto-lei $\mathrm{n}^{\circ}$ 4.073, de 30 de janeiro de 1942. Disponível em: http://www.planalto.gov.br/ccivil_03/decreto-lei/1937-1946/Del4073.htm

BRASIL. Decreto-lei $\mathrm{n}^{\mathrm{o}}$ 4.936, de 7 de novembro de 1942. Disponível em: http://www2.camara.leg.br/legin/fed/declei/1940-1949/decreto-lei-4936-7-novembro1942-414954-publicacaooriginal-1-pe.html

BRASIL. Decreto-lei $\mathrm{n}^{\mathrm{o}}$ 8.621, de 10 de janeiro de 1946. Disponível em: http://www.planalto.gov.br/ccivil_03/decreto-lei/1937-1946/Del8621.htm

BRASIL. Estatuto da Criança e do Adolescente (Lei no 8.069, de 13 de julho de 1990). Disponível em: http://www.planalto.gov.br/ccivil_03/LEIS/L8069.htm

BRASIL. Estado de São Paulo. Decreto n 54.695 de 20 de agosto de 2009. Disponível em: https://www.empregasaopaulo.sp.gov.br/IMO/aprendiz/pdf/Decreto\%20aprendiz\%205469 5\%2020-08-09.pdf 
BRASIL. Lei $\mathrm{n}^{\mathrm{o}}$ 13.420, de 13 de março de 2017. Disponível em: http://www.planalto.gov.br/ccivil_03/_Ato2015-2018/2017/Lei/L13420.htm

BRASIL. Lei $\mathrm{n}^{\circ}$ 8.315, de 23 de dezembro de 1991. Disponível em: http://www.planalto.gov.br/CCIVIL_03/LEIS/L8315.htm

BRASIL. Lei $\mathrm{n}^{\circ}$ 8.706, de 14 de setembro de 1993. Disponível em: http://www.planalto.gov.br/ccivil_03/LEIS/1989_1994/L8706.htm

BRASIL. Lei no 394, de 20 de dezembro de 1996 (Lei de Diretrizes e Bases da Educação nacional). Disponível em: http://www.planalto.gov.br/ccivil_03/LEIS/L9394.htm

BRASIL. Lei $\mathrm{n}^{\mathrm{o}}$ 10.097, de 19 de dezembro de 2000. Disponível em: http://www.planalto.gov.br/ccivil_03/LEIS/L10097.htm

BRASIL. Lei $\mathrm{n}^{\mathrm{o}} 11.180$, de 23 de setembro de 2005. Disponível em: http://www.planalto.gov.br/ccivil_03/_ato2004-2006/2005/lei/111180.htm

BRASIL. Lei $\mathrm{n}^{\mathrm{o}} 11.788$, de 25 de setembro de 2008 Disponível em: http://www.planalto.gov.br/ccivil_03/_Ato2007-2010/2008/Lei/L11788.htm

BRASIL. Ministério do Trabalho. Portaria $n^{\mathbf{o}}$ 723/2012. Disponível em: http://trabalho.gov.br/images/Documentos/Aprendizagem/PORTARIA_723_2.pdf

BRASIL. Ministério da Educação, Resolução do Conselho Nacional de Educação/Conselho Pleno 3, de 18 de dezembro de 2002. Disponível em: http://portal.mec.gov.br/cne/arquivos/pdf/CP032002.pdf

BRASIL. Ministério da Educação, Conselho Nacional de Educação, Câmara de Educação Básica, Resolução $\mathrm{n}^{\circ} 6$ de 20 de setembro de 2012. Disponível em: http://portal.mec.gov.br/index.php?option=com_docman\&view=download\&alias=11663rceb006-12-pdf\&category_slug=setembro-2012-pdf\&Itemid=30192

FRANÇA. Code de l'éducation. Disponível em: https://www.legifrance.gouv.fr/affichCode.do?cidTexte=LEGITEXT000006071191

FRANÇA. Code $\mathrm{du}$ Travail. Disponível em: https://www.legifrance.gouv.fr/affichCode.do?cidTexte=LEGITEXT000006072050 
FRANÇA. Loi du 20 mars 1928. Disponível em: https://www.csn.qc.ca/wpcontent/uploads/archives/LaVieSyndicale_193010_Vol06No12.pdf

ITÁLIA. Decreto Legislativo 15 giugno 2015, n. 81. Disponível em: http://www.normattiva.it/atto/caricaDettaglioAtto?atto.dataPubblicazioneGazzetta=201506-24\&atto.codiceRedazionale=15G00095

OIT. Convenção $\quad \mathrm{n}^{\circ}$ 138. Disponível em: https://www.ilo.org/brasilia/convencoes/WCMS_235872/lang--pt/index.htm OIT. Convenção $\quad \mathrm{n}^{\circ} \quad 182 . \quad$ Disponível em: https://www.ilo.org/brasilia/convencoes/WCMS_236696/lang--pt/index.htm OIT. Recomendação 60, disponível em: https://www.ilo.org/dyn/normlex/es/f?p=1000:12100:8808944251456::NO::P12100_SHO W_TEXT:Y:

OIT. Recomendação $195 . \quad$ Disponível em: https://www.ilo.org/brasilia/convencoes/WCMS_242765/lang--pt/index.htm 
ANEXOS 


\title{
DECRETO No 9.579, DE 22 DE NOVEMBRO DE 2018
}

\author{
(Arts. 43-75)
}

\section{Seção II}

\section{Do aprendiz}

Art. 43. Nas relações jurídicas pertinentes à contratação de aprendizes, será observado o disposto neste Capítulo.

Art. 44. Para fins do disposto neste Capítulo, considera-se aprendiz a pessoa maior de quatorze anos e menor de vinte e quatro anos que celebra contrato de aprendizagem, nos termos do disposto no art. 428 da Consolidação das Leis do Trabalho - CLT, aprovada pelo Decreto-Lei $\mathrm{n}^{\circ} 5.452$, de $1^{\circ}$ de maio de 1943.

Parágrafo único. A idade máxima prevista no caput deste artigo não se aplica a aprendizes com deficiência.

\section{Seção III}

\section{Do contrato de aprendizagem}

Art. 45. Contrato de aprendizagem é o contrato de trabalho especial, ajustado por escrito e por prazo determinado não superior a dois anos, em que o empregador se compromete a assegurar ao aprendiz, inscrito em programa de aprendizagem, formação técnico-profissional metódica compatível com o seu desenvolvimento físico, moral e psicológico, e o aprendiz se compromete a executar, com zelo e diligência, as tarefas necessárias a essa formação.

Parágrafo único. A comprovação da escolaridade de aprendiz com deficiência psicossocial deverá considerar, sobretudo, as habilidades e as competências relacionadas com a profissionalização.

Art. 46. A validade do contrato de aprendizagem pressupõe anotação na Carteira de Trabalho e Previdência Social, matrícula e frequência do aprendiz à escola, caso não tenha concluído o ensino fundamental, e inscrição em programa de aprendizagem desenvolvido sob a orientação de entidade qualificada em formação técnico-profissional metódica.

Art. 47. O descumprimento das disposições legais e regulamentares importará a nulidade do contrato de aprendizagem, nos termos do disposto no $\underline{\text { art. } 9^{\circ} \text { da CLT, aprovada }}$ pelo Decreto-Lei $\mathrm{n}^{\mathrm{o}}$ 5.452, de 1943, situação em que fica estabelecido o vínculo empregatício diretamente com o empregador responsável pelo cumprimento da cota de aprendizagem. 
Parágrafo único. O disposto no caput não se aplica, quanto ao vínculo, a pessoa jurídica de direito público.

\section{Seção IV}

\section{Da formação técnico-profissional e das entidades qualificadas em formação técnico-profissional metódica \\ Subseção I \\ Da formação técnico-profissional}

Art. 48. Para fins do disposto neste Capítulo, considera-se formação técnicoprofissional metódica para os efeitos do contrato de aprendizagem as atividades teóricas e práticas, metodicamente organizadas em tarefas de complexidade progressiva desenvolvidas no ambiente de trabalho.

Parágrafo único. A formação técnico-profissional metódica de que trata o caput será realizada por meio de programas de aprendizagem organizados e desenvolvidos sob a orientação e a responsabilidade de entidades qualificadas em formação técnico-profissional metódica estabelecidas no art. 50.

Art. 49. A formação técnico-profissional do aprendiz obedecerá aos seguintes princípios:

I - garantia de acesso e frequência obrigatória no ensino fundamental;

II - horário especial para o exercício das atividades; e

III - capacitação profissional adequada ao mercado de trabalho.

Parágrafo único. Ao aprendiz com idade inferior a dezoito anos é assegurado o respeito à sua condição peculiar de pessoa em desenvolvimento.

\section{Subseção II}

\section{Das entidades qualificadas em formação técnico-profissional metódica}

Art. 50. Consideram-se entidades qualificadas em formação técnico-profissional metódica:

I - os serviços nacionais de aprendizagem, assim identificados:

a) Serviço Nacional de Aprendizagem Industrial - Senai;

b) Serviço Nacional de Aprendizagem Comercial - Senac;

c) Serviço Nacional de Aprendizagem Rural - Senar;

d) Serviço Nacional de Aprendizagem do Transporte - Senat; e

e) Serviço Nacional de Aprendizagem do Cooperativismo - Sescoop;

II - as escolas técnicas e agrotécnicas de educação; e 
III - as entidades sem fins lucrativos que tenham por objetivos a assistência ao adolescente e à educação profissional, registradas no conselho municipal dos direitos da criança e do adolescente.

$\S 1^{\circ}$ As entidades mencionadas no caput deverão dispor de estrutura adequada ao desenvolvimento dos programas de aprendizagem, de forma a manter a qualidade do processo de ensino e a acompanhar e avaliar os resultados.

$\S 2^{\circ} \mathrm{O}$ Ministério do Trabalho editará, ouvido o Ministério da Educação, normas complementares para dispor sobre a avaliação da competência das entidades a que se refere o inciso III do caput.

$\S 3^{\circ}$ Compete ao Ministério do Trabalho instituir e manter cadastro nacional das entidades qualificadas em formação técnico-profissional metódica e disciplinar a compatibilidade entre o conteúdo e a duração do programa de aprendizagem, com vistas a garantir a qualidade técnico-profissional.

\section{Seção V}

\section{Da contratação de aprendiz}

\section{Subseção I}

\section{Da obrigatoriedade da contratação de aprendiz}

Art. 51. Estabelecimentos de qualquer natureza são obrigados a empregar e matricular nos cursos oferecidos pelos serviços nacionais de aprendizagem o número de aprendizes equivalente a cinco por cento, no mínimo, e quinze por cento, no máximo, dos trabalhadores existentes em cada estabelecimento cujas funções demandem formação profissional.

$\S 1^{\circ}$ Para o cálculo da porcentagem a que se refere o caput, as frações de unidade serão arredondadas para o número inteiro subsequente, hipótese que permite a admissão de aprendiz.

$\S 2^{\circ}$ Para fins do disposto neste Capítulo, considera-se estabelecimento todo complexo de bens organizado para o exercício de atividade econômica ou social do empregador, que se submeta ao regime da CLT, aprovada pelo Decreto-Lei n ${ }^{\circ} 5.452$, de 1943.

Art. 52. Para a definição das funções que demandem formação profissional, deverá ser considerada a Classificação Brasileira de Ocupações do Ministério do Trabalho.

$\S 1^{\circ}$ Ficam excluídas da definição a que se refere o caput as funções que demandem, para o seu exercício, habilitação profissional de nível técnico ou superior, ou, ainda, as funções que estejam caracterizadas como cargos de direção, de gerência ou de confiança, 
nos termos do disposto no inciso II do caput e no parágrafo único do art. 62 e no $\$ 2^{\circ}$ do art. 224 da CLT, aprovada pelo Decreto-Lei no 5.452 , de 1943.

$\S 2^{\circ}$ Deverão ser incluídas na base de cálculo todas as funções que demandem formação profissional, independentemente de serem proibidas para menores de dezoito anos.

Art. 53. A contratação de aprendizes deverá atender, prioritariamente, aos adolescentes entre quatorze e dezoito anos, exceto quando:

I - as atividades práticas da aprendizagem ocorrerem no interior do estabelecimento e sujeitarem os aprendizes à insalubridade ou à periculosidade, sem que se possa elidir o risco ou realizá-las integralmente em ambiente simulado;

II - a lei exigir, para o desempenho das atividades práticas, licença ou autorização vedada para pessoa com idade inferior a dezoito anos; e

III - a natureza das atividades práticas for incompatível com o desenvolvimento físico, psicológico e moral dos adolescentes aprendizes.

Parágrafo único. As atividades práticas da aprendizagem a que se refere o caput deverão ser designadas aos jovens de dezoito a vinte e quatro anos.

Art. 54. Ficam excluídos da base de cálculo de que trata o caput do art. 51 os empregados que executem os serviços prestados sob o regime de trabalho temporário, instituído pela Lei $\mathrm{n}^{\circ} 6.019$, de 3 de janeiro de 1973, e os aprendizes já contratados.

Parágrafo único. Na hipótese de empresas que prestem serviços especializados para terceiros, independentemente do local onde sejam executados, os empregados serão incluídos exclusivamente na base de cálculo da prestadora.

Art. 55. Na hipótese de os serviços nacionais de aprendizagem não oferecerem cursos ou vagas suficientes para atender à demanda dos estabelecimentos, esta poderá ser suprida por outras entidades qualificadas em formação técnico-profissional metódica, observado o disposto no art. 50.

Parágrafo único. A insuficiência de cursos ou vagas a que se refere o caput será verificada pela inspeção do trabalho.

Art. 56. Ficam dispensadas da contratação de aprendizes:

I - as microempresas e as empresas de pequeno porte; e

II - as entidades sem fins lucrativos que tenham por objetivo a educação profissional.

\section{Subseção II}

\section{Das espécies de contratação do aprendiz}

Art. 57. A contratação do aprendiz deverá ser efetivada diretamente pelo estabelecimento que se obrigue ao cumprimento da cota de aprendizagem ou, 226 
supletivamente, pelas entidades sem fins lucrativos a que se refere o inciso III do caput do art. 50.

$\S 1^{\mathrm{o}} \mathrm{Na}$ hipótese de contratação de aprendiz diretamente pelo estabelecimento que se obrigue ao cumprimento da cota de aprendizagem, este assumirá a condição de empregador, hipótese em que deverá inscrever o aprendiz em programa de aprendizagem a ser ministrado pelas entidades indicadas no art. 50.

$\S 2^{\circ}$ A contratação de aprendiz por intermédio de entidade sem fins lucrativos, para fins do cumprimento da obrigação prevista no caput do art. 51, somente deverá ser formalizada após a celebração de contrato entre o estabelecimento e a entidade sem fins lucrativos, no qual, entre outras obrigações recíprocas, serão estabelecidas as seguintes:

I - a entidade sem fins lucrativos, simultaneamente ao desenvolvimento do programa de aprendizagem, assumirá a condição de empregador, com todos os ônus dela decorrentes, e assinará a Carteira de Trabalho e Previdência Social do aprendiz, na qual anotará, no espaço destinado às anotações gerais, a informação de que o contrato de trabalho específico decorrerá de contrato firmado com determinado estabelecimento para fins do cumprimento de sua cota de aprendizagem; e

II - o estabelecimento assumirá a obrigação de proporcionar ao aprendiz a experiência prática da formação técnico-profissional metódica a que este será submetido.

Art. 58. A contratação do aprendiz por empresas públicas e sociedades de economia mista ocorrerá de forma direta, nos termos do disposto no $\S 1^{\circ}$ do art. 57, hipótese em que será realizado processo seletivo por meio de edital, ou nos termos do disposto no $\S 2^{\circ}$ do referido artigo.

Parágrafo único. A contratação do aprendiz por órgãos e entidades da administração pública direta, autárquica e fundacional observará regulamento específico, hipótese em que não se aplica o disposto neste Capítulo.

\section{Seção VI}

\section{Dos direitos trabalhistas e das obrigações acessórias Subseção I \\ Da remuneração}

Art. 59. Ao aprendiz, exceto se houver condição mais favorável, será garantido o salário mínimo-hora.

Parágrafo único. Para fins do disposto neste Capítulo, entende-se por condição mais favorável aquela estabelecida no contrato de aprendizagem ou prevista em convenção ou 
acordo coletivo de trabalho, em que se especifique o salário mais favorável ao aprendiz e o piso regional de que trata a Lei Complementar $n^{\circ} 103$, de 14 de julho de 2000.

\section{Subseção II}

\section{Da jornada}

Art. 60. A jornada de trabalho do aprendiz não excederá seis horas diárias.

$\S 1^{\circ}$ Para os aprendizes que já tenham concluído o ensino fundamental, a jornada de trabalho poderá ser de até oito horas diárias, desde que nessa carga horária sejam computadas as horas destinadas à aprendizagem teórica.

$\S 2^{\circ}$ A jornada semanal do aprendiz inferior a vinte e cinco horas não caracterizará trabalho em regime de tempo parcial, de que trata o art. 58-A da CLT, aprovada pelo Decreto-Lei n ${ }^{\circ}$ 5.452, de 1943.

Art. 61. São vedadas a prorrogação e a compensação de jornada de trabalho.

Art. 62. A jornada de trabalho do aprendiz compreenderá as horas destinadas às atividades teóricas e práticas, simultâneas ou não, e caberá à entidade qualificada em formação técnico-profissional metódica estabelece-las no plano do curso.

Art. 63. Na hipótese de o aprendiz menor de dezoito anos ser empregado em mais de um estabelecimento, as horas da jornada de trabalho em cada um dos estabelecimentos serão totalizadas.

Parágrafo único. Para estabelecer a jornada de trabalho do aprendiz menor de dezoito anos, a entidade qualificada em formação técnico-profissional metódica considerará os direitos assegurados pela Lei no 8.069, de 1990 - Estatuto da Criança e do Adolescente.

\section{Subseção III}

\section{Das atividades teóricas e práticas}

Art. 64. As aulas teóricas do programa de aprendizagem deverão ocorrer em ambiente físico adequado ao ensino e com meios didáticos apropriados.

$\S 1^{\mathrm{o}}$ As aulas teóricas poderão ocorrer sob a forma de aulas demonstrativas no ambiente de trabalho, hipótese em que é vedada qualquer atividade laboral do aprendiz, ressalvado o manuseio de materiais, ferramentas, instrumentos e assemelhados.

$\S 2^{\circ}$ É vedado ao responsável pelo cumprimento da cota de aprendizagem cometer ao aprendiz atividades diversas daquelas previstas no programa de aprendizagem.

Art. 65. As aulas práticas poderão ocorrer na própria entidade qualificada em formação técnico-profissional metódica ou no estabelecimento contratante ou concedente da experiência prática do aprendiz. 
$\S 1^{\circ} \mathrm{Na}$ hipótese de o ensino prático ocorrer no estabelecimento, será formalmente designado pela empresa, ouvida a entidade qualificada em formação técnico-profissional metódica, um empregado monitor responsável pela coordenação de exercícios práticos e pelo acompanhamento das atividades do aprendiz no estabelecimento, em conformidade com o disposto no programa de aprendizagem.

$\S 2^{\circ}$ A entidade responsável pelo programa de aprendizagem fornecerá aos empregadores e ao Ministério do Trabalho, quando solicitado, cópia do projeto pedagógico do programa.

$\S 3^{\circ}$ Para fins da experiência prática de acordo com a organização curricular do programa de aprendizagem, o empregador que mantenha mais de um estabelecimento no mesmo Município poderá centralizar as atividades práticas correspondentes em um de seus estabelecimentos.

$\S 4^{\circ}$ Nenhuma atividade prática poderá ser desenvolvida no estabelecimento em desacordo com as disposições do programa de aprendizagem.

Art. 66. O estabelecimento contratante cujas peculiaridades da atividade ou dos locais de trabalho constituam embaraço à realização das aulas práticas, além de poder ministrá-las exclusivamente nas entidades qualificadas em formação técnico profissional, poderá requerer junto à unidade descentralizada do Ministério do Trabalho a assinatura de termo de compromisso para o cumprimento da cota em entidade concedente da experiência prática do aprendiz.

$\S 1^{\circ}$ Compete ao Ministério do Trabalho definir:

I - os setores da economia em que a aula prática poderá ser ministrada nas entidades concedentes; e

II - o processamento do pedido de assinatura de termo de compromisso.

$\S 2^{\circ}$ Para fins do disposto neste Capítulo, consideram-se entidades concedentes da experiência prática do aprendiz:

I - órgãos públicos;

II - organizações da sociedade civil, nos termos do disposto no art. $2^{\circ}$ da Lei $n^{\circ} 13.019$, de 31 de julho de 2014; e

III - unidades do sistema nacional de atendimento socioeducativo.

$\S 3^{\circ}$ Firmado o termo de compromisso com o Ministério do Trabalho, o estabelecimento contratante e a entidade qualificada por ele já contratada deverão firmar, conjuntamente, parceria com uma das entidades concedentes para a realização das aulas práticas. 
$\S 4^{\circ}$ Compete à entidade qualificada o acompanhamento pedagógico das aulas práticas.

$\S 5^{\circ}$ A seleção dos aprendizes será realizada a partir do cadastro público de emprego, disponível no sítio eletrônico Emprega Brasil, do Ministério do Trabalho, e deverá priorizar a inclusão de jovens e adolescentes em situação de vulnerabilidade ou risco social, tais como:

I - adolescentes egressos do sistema socioeducativo ou em cumprimento de medidas socioeducativas;

II - jovens em cumprimento de pena no sistema prisional;

III - jovens e adolescentes cujas famílias sejam beneficiárias de programas de transferência de renda;

IV - jovens e adolescentes em situação de acolhimento institucional;

$\mathrm{V}$ - jovens e adolescentes egressos do trabalho infantil;

VI - jovens e adolescentes com deficiência;

VII - jovens e adolescentes matriculados em instituição de ensino da rede pública, em nível fundamental, médio regular ou médio técnico, incluída a modalidade de Educação de Jovens e Adultos; e

VIII - jovens desempregados e com ensino fundamental ou médio concluído em instituição de ensino da rede pública.

$\S 6^{\circ}$ Os percentuais a serem cumpridos na forma alternativa e no sistema regular deverão constar do termo de compromisso firmado com o Ministério do Trabalho, com vistas ao adimplemento integral da cota de aprendizagem, observados, em todos as hipóteses, os limites previstos na Seção IV do Capítulo IV do Título III da CLT, aprovada pelo DecretoLei $\mathrm{n}^{\circ} 5.452$, de 1943 , e a contratação do percentual mínimo no sistema regular.

\section{Subseção IV}

\section{Do Fundo de Garantia do Tempo de Serviço}

Art. 67. O disposto no $§ 7^{\circ}$ do art. 15 da Lei $\mathrm{n}^{\circ} 8.036$, de 11 de maio de 1990 , se aplica à alíquota de contribuição ao Fundo de Garantia do Tempo de Serviço - FGTS para o contrato de aprendizagem.

Parágrafo único. A contribuição ao FGTS de que trata o caput corresponderá a dois por cento da remuneração paga ou devida, no mês anterior, ao aprendiz. 


\section{Subseção V \\ Das férias}

Art. 68. As férias do aprendiz coincidirão, preferencialmente, com as férias escolares, vedado ao empregador estabelecer período diverso daquele definido no programa de aprendizagem.

\section{Subseção VI}

\section{Dos efeitos dos instrumentos coletivos de trabalho}

Art. 69. As convenções e os acordos coletivos apenas estenderão suas cláusulas sociais ao aprendiz quando expressamente previsto e desde que não excluam ou reduzam o alcance dos dispositivos tutelares que lhes são aplicáveis.

\section{Subseção VII}

\section{Do vale-transporte}

Art. 70. É assegurado ao aprendiz o direito ao benefício previsto na Lei $\mathrm{n}^{\circ} 7.418$, de 16 de dezembro de 1985 , que institui o vale-transporte.

\section{Subseção VIII}

\section{Das hipóteses de extinção e rescisão de contrato de aprendizagem}

Art. 71. O contrato de aprendizagem extinguir-se-á no seu termo ou quando o aprendiz completar vinte e quatro anos, exceto na hipótese de aprendiz com deficiência, ou, ainda antecipadamente, nas seguintes hipóteses:

I - desempenho insuficiente ou inadaptação do aprendiz;

II - falta disciplinar grave;

III - ausência injustificada à escola que implique perda do ano letivo; e

IV - a pedido do aprendiz.

Parágrafo único. Nas hipóteses de extinção ou rescisão do contrato de aprendizagem, o empregador deverá contratar novo aprendiz, nos termos do disposto neste Decreto, sob pena de infração ao disposto no art. 429 da CLT.

Art. 72. Para fins do disposto no art. 71, serão observadas as seguintes disposições:

I - o desempenho insuficiente ou inadaptação do aprendiz referente às atividades do programa de aprendizagem será caracterizado por meio de laudo de avaliação elaborado pela entidade qualificada em formação técnico-profissional metódica;

II - a falta disciplinar grave será caracterizada por quaisquer das hipóteses previstas no art. 482 da CLT, aprovada pelo Decreto-Lei n ${ }^{\circ}$ 5.452, de 1943; e

III - a ausência injustificada às aulas que implique perda do ano letivo será caracterizada por meio de declaração da instituição de ensino. 
Art. 73. O disposto nos art. 479 e art. 480 da CLT, aprovada pelo Decreto-Lei $\mathrm{n}^{\circ}$

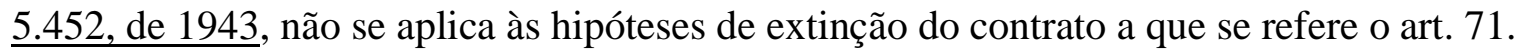

\section{Seção IV}

\section{Do certificado de qualificação profissional de aprendizagem}

Art. 74. Aos aprendizes que concluírem os programas de aprendizagem com aproveitamento será concedido pela entidade qualificada em formação técnico-profissional metódica o certificado de qualificação profissional.

Art. 75. O certificado de qualificação profissional a que se refere o art. 74 deverá enunciar o título e o perfil profissional para a ocupação em que o aprendiz tenha sido qualificado. 


\section{PORTARIA DO MINISTÉRIO DO TRABALHO E EMPREGO - MTE No 723 DE}

23 DE ABRIL 2012

O MINISTRO DE ESTADO DO TRABALHO, no uso das atribuições que lhe confere o inciso II do parágrafo único do art. 87 da Constituição, e tendo em vista o disposto no $\S 2^{\circ}$ do art. $8^{\circ}$ e art. 32 do Decreto $n^{\circ} 5.598$, de $1^{\circ}$ de dezembro de 2005, resolve:

Art. $1^{\circ}$ Criar o Cadastro Nacional de Aprendizagem Profissional - CNAP, destinado ao cadastramento das entidades qualificadas em formação técnico-profissional metódica definidas no art. $8^{\circ}$ do Decreto $n^{\circ} 5.598$, de $1^{\circ}$ de dezembro de 2005.

$\S 1^{\circ}$ Para inserção no CNAP as entidades a que se referem os incisos II e III do art. 430 da CLT serão submetidas às normas de avaliação de competência previstas nesta Portaria, relativas à verificação da aptidão da entidade para ministrar programas de formação técnicoprofissional que permitam a inclusão de aprendizes no mercado de trabalho. (Alterado pela portaria 634 de 09 de agosto de 2018)

$\S 2^{\circ}$ As entidades referidas no inciso I do art. 430 da CLT devem se inscrever no CNAP na forma do art. $3^{\circ}$ e do art. $5^{\circ}$ desta portaria, firmar o termo de compromisso nos termos no do art. $4^{\circ}$ nos moldes do $\$ 3^{\circ}$, II e III, e informar as turmas criadas e os aprendizes nelas matriculados.(Alterado pela portaria 634 de 09 de agosto de 2018)

$\S 3^{\circ}$ As entidades referidas no caput do Art. 430 da CLT, devem se inscrever no CNAP, na forma do art. $3^{\circ}$, e fornecer as informações previstas no inciso IV do art. $5^{\circ}$, as turmas criadas e os aprendizes nelas matriculados, e não se submetem às normas de avaliação de competência previstas nesta Portaria, referentes ao programa de aprendizagem inserido. (Alterado pela portaria 634 de 09 de agosto de 2018)

Art. $2^{\circ}$ Compete à Secretaria de Políticas Públicas de Emprego - SPPE, do Ministério do Trabalho e Emprego - MTE:

I - autorizar a inserção das entidades no CNAP, após a avaliação de competência e verificação de cumprimento das regras e requisitos previstos nesta Portaria;

II - operacionalizar, sistematizar, monitorar e aperfeiçoar o CNAP e o Catálogo Nacional de Programas de Aprendizagem Profissional - CONAP;

III - orientar e padronizar a oferta de programas da aprendizagem profissional, em consonância com a Classificação Brasileira de Ocupações - CBO;

IV - efetuar a avaliação de competência das entidades qualificadas em formação técnicoprofissional metódica mencionadas no incisos II e III do art. 430 da CLT, validar os 
programas de aprendizagem de todas as entidades mencionadas no referido artigo; e (Alterado pela portaria 634 de 09 de agosto de 2018)

$\mathrm{V}$ - divulgar os programas de aprendizagem validados no CNAP na página eletrônica do MTE na rede mundial de computadores - internet, com objetivo de instrumentalizar os órgãos de fiscalização e promover informações a jovens, adolescentes e pessoas com deficiência, empregadores e sociedade civil, com a descrição: (Alterado pela portaria 634 de 09 de agosto de 2018)

a) do perfil profissional da formação;

b) da carga horária teórica e prática; e

c) revogado. (Alterado pela portaria 634 de 09 de agosto de 2018)

d) demais informações da turma solicitadas pela plataforma. (Alterado pela portaria 634 de 09 de agosto de 2018)

VI - desenvolver procedimentos para o monitoramento e a avaliação sistemáticos da aprendizagem, com ênfase na qualidade pedagógica e na efetividade social.

Art. $3^{\circ}$ A inscrição das entidades de que trata o art. $1^{\circ}$ desta Portaria no CNAP, dos respectivos programas, das turmas e dos aprendizes nelas matriculados deve ser efetuada por meio do sistema Mais Aprendiz, na internet no endereço www.maisaprendiz.mte.gov.br. (Alterado pela portaria 634 de 09 de agosto de 2018)

$\S 1^{\circ}$ Os programas de aprendizagem, elaborados em consonância com as regras do Catálogo Nacional de Programas de Aprendizagem Profissional - CONAP previsto no art. $8^{\circ}$ desta Portaria, devem ser inscritos por município no CNAP para avaliação da competência da entidade.

$\S 2^{\circ} \mathrm{O}$ programa de aprendizagem inserido no CNAP tem prazo de vigência de dois anos contados a partir de sua validação no sistema Mais Aprendiz.

$\S 3^{\circ} \mathrm{O}$ prazo de vigência do programa de aprendizagem profissional pode ser prorrogado por igual período salvo se houver quaisquer alterações legislativas ou em normas referentes à(s) ocupação(s) objeto do programa de aprendizagem.

Art. $4^{\mathbf{0}}$ Após a inscrição das escolas técnicas, das entidades sem fins lucrativos, e das entidades de prática desportiva das diversas modalidades filiadas ao Sistema Nacional do Desporto e aos sistemas de Desporto dos Estados, do Distrito Federal e dos Municípios, nos termos do art. $1, \S 1$ e 2 , será gerado pelo Sistema do Cadastro Nacional de Aprendizagem CNAP o Termo de Compromisso da Entidade e o Termo de Compromisso do Programa de Aprendizagem, que devem ser assinados digitalmente, no referido sistema, por meio do e- 
CNPJ que contenha a mesma base da Pessoa Jurídica ou e-CPF do representante legal da entidade qualificadora no cadastro. (Alterado pela portaria 634 de 09 de agosto de 2018) $\S 1^{\circ}$ Cabe à coordenação de fiscalização de aprendizagem de cada Superintendência Regional do Trabalho - SRTb conferir, atestar e registrar o recebimento da documentação anexada e do termo de compromisso no Cadastro Nacional de Aprendizagem- CNAP.

$\S 2^{\circ} \mathrm{O}$ Termo de Compromisso das entidades qualificadoras mencionadas no caput deste artigo deve ser acompanhado de comprovação de:

I - registro no Conselho Municipal da Criança e do Adolescente, quando se tratar de Entidade Qualificadora Sem Fins Lucrativos, referida no inciso II do artigo 430 da CLT;

II - parecer do Conselho Estadual de Educação, quando se tratar de Escola Técnica referida no inciso I do artigo 430 da CLT;

III - comprovante de filiação ao Sistema Nacional do Desporto e/ou sistema de Desporto dos Estados, do Distrito Federal e dos Municípios.

$\S 3^{\circ} \mathrm{O}$ Termo de Compromisso do programa de aprendizagem deve ser acompanhado de comprovação de:

I - adequação da proposta pedagógica aos princípios e diretrizes desta Portaria;

II - existência de quadro técnico -docente devidamente qualificado; e

III - estrutura adequada ao desenvolvimento dos programas de aprendizagem, nos termos do disposto no $\S 1^{\circ}$ art. 430 da CLT.

$\S 4^{\circ}$ Caso seja identificada pela fiscalização do trabalho alguma inadequação em relação aos documentos citados nos $\S 2^{\circ}$ e $\S 3^{\circ}$, o termo de compromisso não será registrado no sistema nos termos do $\S 1^{\circ}$ deste artigo. Neste caso, o Auditor Fiscal do Trabalho registrará parecer justificando a negativa, em um prazo máximo de 30 dias.

$\S 5^{\circ}$ Quando a inadequação se referir a documentação do $\S 2^{\circ}$, a entidade qualificadora não estará apta a cadastrar e ministrar programas de aprendizagem. Caso a inadequação se refira a documentação do $\S 3^{\circ}$, o programa de aprendizagem não será validado.

Art. $5^{\circ}$ A inscrição do programa de aprendizagem deve ser feita nos moldes do art. $3^{\circ}$ desta Portaria e a entidade deve fornecer, no mínimo, as seguintes informações: (Alterado pela portaria 634 de 09 de agosto de 2018)

I - público participante do programa de aprendizagem, com informação de faixa etária;

II - revogado;

III - revogado; 
IV - estrutura do programa de aprendizagem e sua duração em horas, em função da ocupação(s) objeto do programa a ser desenvolvido e do perfil do público participante, contendo:

a) definição e ementa dos programas;

b) organização curricular em módulos, núcleos ou etapas com sinalização do caráter propedêutico ou profissionalizante de cada um deles;

c) respectivas cargas horárias teóricas e práticas, fixadas na forma dos $\S \S 2^{\circ}$ e $3^{\circ}$ do art. 10 desta Portaria; e

d) atividades práticas desenvolvidas no local da prática laboral, em conformidade com as atividades previstas na tabela de atividades da CBO objeto do programa.

$\mathrm{V}$ - infraestrutura física, como equipamentos, instrumentos e instalações necessárias para as ações do programa, com adequação aos conteúdos, à duração e à quantidade e perfil dos participantes;

VI - recursos humanos: quantidade e qualificação do pessoal técnico-docente e de apoio envolvido na execução do programa de aprendizagem, adequadas ao conteúdo pedagógico, duração, quantidade e perfil dos participantes, e identificação dos mecanismos de contratação e permanência de educadores no quadro profissional, com especificação do profissional da entidade responsável pelo acompanhamento das atividades práticas dos aprendizes na empresa;

VII - mecanismos de acompanhamento e avaliação do programa de aprendizagem, mediante registro documental das atividades teóricas e práticas pela entidade formadora, com a participação do aprendiz e da empresa; e

VIII - mecanismos para propiciar a inserção dos aprendizes no mercado de trabalho após o término do contrato de aprendizagem.

Art. $6^{\circ} \mathrm{O}$ cadastro das escolas técnicas, entidades sem fins lucrativos e entidades de prática desportiva das diversas modalidades filiadas ao Sistema Nacional do Desporto e aos Sistemas de Desporto dos Estados, do Distrito Federal e dos Municípios no Cadastro Nacional de Aprendizagem - CNAP, será submetido à avaliação técnica da SPPE e SRTE, de acordo com suas competências, podendo a entidade se tornar apta a cadastrar programas de aprendizagem. (Alterado pela portaria 634 de 09 de agosto de 2018)

$\S 1^{\circ} \mathrm{A}$ incompatibilidade do cadastro da entidade e dos programas de aprendizagem com as regras estabelecidas nesta Portaria será informada pela SPPE e SRTb à entidade por mensagem eletrônica, e as inscrições no CNAP ficarão sobrestadas até a regularização de pendências. 
$\S 2^{\circ}$ Durante a análise do programa de aprendizagem para inserção no CNAP, a SPPE poderá solicitar a colaboração de outros órgãos, conselhos e demais entidades envolvidos com a ocupação objeto do programa de aprendizagem ou com o seu público alvo.

$\S 3^{\circ}$ Os programa validados e a indicação de turmas previstas e/ou confirmadas serão disponibilizadas no portal do Ministério do Trabalho para consulta pública.

$\S 4^{\circ}$ Somente a partir da validação do programa e durante seu período de vigência, a entidade estará autorizada a iniciar turmas.

$\S 5^{\circ}$ Os programas de aprendizagem devem ser elaborados e desenvolvidos pela entidade em consonância com esta Portaria, e devem ser inscritos e validados no CNAP para cada município onde a entidade deseja atuar.

Art. $6^{\circ}$-A As entidades formadoras ficam obrigadas a registrar no CNAP as turmas previstas e/ ou confirmadas e realizar o cadastro dos aprendizes vinculados a essas turmas. (Alterado pela portaria 634 de 09 de agosto de 2018)

$\S 1^{\circ} \mathrm{O}$ cadastro da turma deve conter os seguintes itens:

I - a quantidade máxima de aprendizes;

II - carga horária diária, distribuída em calendário, com a indicação de carga horária teórica e prática;

III - distribuição curricular em módulos se houver;

IV - especificação da carga horária teórica básica, teórica específica e prática.

$\S 2^{\circ} \mathrm{O}$ cadastro do aprendiz deve conter:

I - os dados gerais de identificação do aprendiz;

II - escolaridade;

III - informações do estabelecimento responsável pelo cumprimento da cota;

IV - inicio e término do contrato de aprendizagem;

$\mathrm{V}$ - perfil socioeconômico;

VI - a CBO constante no contrato de aprendizagem.

$\S 3^{\circ} \mathrm{O}$ Ministério do Trabalho realizará monitoramento da inserção dos dados de turmas e aprendizes no CNAP.

$\S 4^{\circ}$ Constatada divergência com a base de dados deste Ministério ou omissão na informação dos dados, a entidade será notificada e terá o prazo máximo de 30 dias para atualização e/ou correção dos dados.

$\S 5^{\circ}$ Em caso de não correção no prazo estabelecido no§4 $4^{\circ}$ a entidade será suspensa até que a incorreção seja sanada. 
Art. $7^{\circ}$ Quando identificada pela fiscalização a inadequação dos programas de aprendizagem à legislação ou a sua execução em desacordo com as informações constantes do CNAP, a chefia da inspeção do trabalho da SRTb requisitará à SPPE a suspensão do cadastro da entidade ou do programa. (Alterado pela portaria 634 de 09 de agosto de 2018)

$\S 1^{\circ}$ Quando suspenso o cadastro da entidade, não serão permitidos novos cadastramentos, validações e abertura de turmas.

$\S 2^{\circ}$ Quando suspenso o programa, a entidade responsável por este não poderá abrir novas turmas no programa suspenso, cadastrar e/ou validar novos programas para a mesma ocupação, arco ocupacional ou itinerário formativo.

$\S 3^{\circ}$ Quando a entidade matriz, filial ou unidade sem CNPJ estiver suspensa ou possuir algum programa suspenso, esta não poderá cadastrar e/ou ter validados programas na modalidade à distância em nível nacional.

$\S 4^{\circ}$ Os motivos que justifiquem a suspensão de entidades ou dos programas de aprendizagem devem ser fundamentados em relatório de fiscalização, do qual deve ser enviada cópia à SPPE, juntamente com a solicitação prevista no caput deste artigo.

$\S 5^{\circ}$ A suspensão da entidade qualificadora motivada pela hipótese prevista no caput deste artigo abrange somente as entidades constantes do referido relatório:

I - quando se tratar de suspensão de uma entidade matriz serão suspensas automaticamente suas unidades sem CNPJ.

$\S 6^{\circ}$ Cabe à SPPE dar ciência do relatório às chefias de fiscalização das localidades em que forem identificadas filiais das respectivas entidades.

$\S 7^{\circ}$ A entidade ou o programa poderão ser suspensos por um ano em caso de reincidência.

$\S 8^{\circ}$ A entidade será suspensa nacionalmente por cinco anos caso atue em desacordo com a legislação em dois ou mais estados.

Art. $8^{\circ}$ Os programas de aprendizagem devem ser elaborados em conformidade com o Catálogo Nacional de Programas de Aprendizagem Profissional - CONAP, publicado na página eletrônica do MTb.

Parágrafo único. Cabe à SPPE revisar o CONAP e promover a publicação das alterações na página eletrônica do $\mathrm{MTb}$ na internet, na periodicidade necessária para contemplar a evolução técnica e tecnológica do setor produtivo e promover oportunidades de inclusão social e econômica dos adolescentes e jovens de forma sustentável e por meio do trabalho decente. 
Art. $9^{\circ}$ A formação profissional em cursos de nível inicial e técnico constantes do CONAP relaciona-se à ocupação codificada na Classificação Brasileira de Ocupações - CBO. (Alterado pela portaria 634 de 09 de agosto de 2018)

$\S 1^{\circ} \mathrm{O}$ código da $\mathrm{CBO}$ a que se refere o caput deste artigo deve constar do contrato de trabalho do aprendiz e ser anotado em sua Carteira de Trabalho e Previdência Social - CTPS. $\S 2^{\circ}$ Quando o curso for classificado no CONAP como desenvolvido na metodologia dos arcos ocupacionais ou itinerários formativos, na CTPS do aprendiz deverá constar o código CBO com a melhor condição salarial e/ou de empregabilidade.

$\S 3^{\circ} \mathrm{Na}$ hipótese da contratação acontecer nos moldes do $\S 2^{\circ}$, deverá ser especificado nas anotações gerais da CTPS o arco ocupacional ou itinerário formativo utilizado com seus respectivos códigos CBOs.

Art. 10. As entidades ofertantes de programas de aprendizagem em nível de formação inicial devem se adequar ao CONAP e atender às seguintes diretrizes: (Alterado pela portaria 634 de 09 de agosto de 2018)

I - diretrizes gerais:

a) qualificação social e profissional adequada às demandas e diversidades dos adolescentes, em conformidade com o disposto no art. $7^{\circ}$, parágrafo único, do Decreto $\mathrm{n}^{\mathrm{o}} 5.598$, de 2005 ;

b) caracterizar-se como início de um itinerário formativo;

c) promoção social no mundo de trabalho pela aquisição de conhecimento e habilidades que contribuam para o itinerário formativo a ser desenvolvido ao longo da vida do aprendiz;

d) contribuição para a elevação do nível de escolaridade do aprendiz;

e) garantia das adequações para a aprendizagem de pessoas com deficiência conforme estabelecem os arts. $2^{\circ}$ e 24 da Convenção da Organização das Nações Unidas - ONU sobre os Direitos das Pessoas com Deficiência, promulgada pelo Decreto ${ }^{\circ} 6.949$, de 25 de agosto de 2009, e os arts. 28 e 29 do Decreto $n^{\circ} 3.298$, de 20 de dezembro de 1999;

f) atendimento às necessidades dos adolescentes e jovens do campo e dos centros urbanos, que exijam um tratamento diferenciado no mercado de trabalho em razão de suas especificidades ou exposição a situações de maior vulnerabilidade social, conforme definido na política nacional de assistência social, particularmente no que se refere à baixa escolaridade e às dimensões de gênero, raça, etnia, orientação sexual e deficiência; e

g) articulação de esforços nas áreas de educação, do trabalho e emprego, do esporte e lazer, da cultura e da ciência e tecnologia e assistência social. (Alterado pela portaria 1005 de 01 de julho de 2013)

II - diretrizes curriculares: 
a) desenvolvimento pessoal, social e profissional do adolescente e do jovem, na qualidade de trabalhador e cidadão;

b) perfil profissional, conhecimentos e habilidades requeridas para o desempenho da ocupação objeto de aprendizagem e descritos na CBO;

c) Referências Curriculares Nacionais aprovadas pelo Conselho Nacional de Educação, quando pertinentes;

d) potencialidades do mercado local e regional de trabalho e as necessidades dos empregadores dos ramos econômicos para os quais se destina a formação profissional;

e) ingresso de pessoas com deficiência e de adolescentes e jovens em situação de vulnerabilidade social nos programas de aprendizagem, condicionado à sua capacidade de aproveitamento e não ao seu nível de escolaridade; e

f) outras demandas do mundo do trabalho, vinculadas ao empreendedorismo e à economia solidária;

III - conteúdos de formação humana e científica devidamente contextualizados:

a) comunicação oral e escrita, leitura e compreensão de textos e inclusão digital;

b) raciocínio lógico-matemático, noções de interpretação e análise de dados estatísticos; c) diversidade cultural brasileira;

d) organização, planejamento e controle do processo de trabalho e trabalho em equipe;

e) noções de direitos trabalhistas e previdenciários, de saúde e segurança no trabalho e do Estatuto da Criança e do Adolescente - ECA;

f) direitos humanos, com enfoque no respeito à orientação sexual, raça, etnia, idade, credo religioso ou opinião política;

g) educação fiscal para o exercício da cidadania;

h) formas alternativas de geração de trabalho e renda com enfoque na juventude;

i) educação financeira e para o consumo e informações sobre o mercado e o mundo do trabalho;

j) prevenção ao uso de álcool, tabaco e outras drogas;

k) educação para a saúde sexual reprodutiva, com enfoque nos direitos sexuais e nos direitos reprodutivos e relações de gênero;

1) políticas de segurança pública voltadas para adolescentes e jovens; e

m) incentivo à participação individual e coletiva, permanente e responsável, na preservação do equilíbrio do meio ambiente, com enfoque na defesa da qualidade ambiental como um valor inseparável do exercício da cidadania. 
$\S 1^{\circ}$ As atividades teóricas e práticas da formação do aprendiz devem ser pedagogicamente articuladas entre si sob a forma de itinerários formativos, com complexidade progressiva possibilitando ao aprendiz o desenvolvimento de sua cidadania e a compreensão das características do mundo do trabalho.

$\S 2^{\circ}$ Para definição da carga horária teórica do programa de aprendizagem, a instituição deve utilizar como parâmetro a carga horária dos cursos técnicos homologados pelo Ministério da Educação - MEC, aplicando-se, no mínimo, quarenta por cento da carga horária do curso correspondente ou quatrocentas horas, o que for maior.

$\S 3^{\circ}$ A carga horária teórica deve representar no mínimo trinta por cento e, no máximo, cinqüienta por cento do total de horas do programa de aprendizagem.

§4 $4^{\circ}$ A carga horária específica, relativa à(s) ocupação(s) objeto do programa de aprendizagem, deverá corresponder no mínimo a 40\% do total da carga horária teórica, exceto para programas voltados para o público do art. 10, inciso I, alínea "f'.

Art. 11. A parte teórica do contrato de aprendizagem deve ser desenvolvida pela entidade formadora, aplicando-se no mínimo $10 \%$ da carga horária teórica no início do contrato antes do encaminhamento para a prática profissional e distribuindo-se as demais horas no decorrer de todo o período do contrato de forma a garantir a complexidade progressiva das atividades práticas. (Alterado pela portaria 634 de 09 de agosto de 2018)

$\S 1^{\circ}$ A carga horária prática do curso poderá ser desenvolvida, total ou parcialmente, em condições laboratoriais, quando essenciais à especificidade da ocupação objeto do curso, ou quando o local de trabalho não oferecer condições de segurança e saúde ao aprendiz.

$\S 2^{\circ} \mathrm{Na}$ elaboração da parte específica dos programas de aprendizagem, as entidades devem contemplar os conteúdos e habilidades requeridas para o desempenho das ocupações objeto da aprendizagem descritas na $\mathrm{CBO}$.

Art. 12 Os cursos de nível técnico serão reconhecidos como programas de aprendizagem profissional para efeito de cumprimento do art. 428 e seguintes da Consolidação das Leis do Trabalho - CLT, aprovada pelo Decreto-Lei $\mathrm{n}^{\mathrm{o}} 5.452$, de $1^{\circ}$ de maio de 1943, quando ofertados por instituições de ensino devidamente regularizadas perante o respectivo órgão competente do sistema de ensino e validados de acordo com os critérios previstos nesta Portaria. (Alterado pela portaria 634 de 09 de agosto de 2018)

$\S 1^{\circ}$ A critério das instituições de ensino federais ou dos órgãos competentes nos sistemas estaduais, as atividades práticas realizadas durante a vigência do contrato de aprendizagem poderão ser reconhecidas para efeitos de contagem da carga-horária de estágio obrigatório, desde que explicitada tal previsão no projeto pedagógico do curso e desde que os termos 
desta equivalência constem no Termo de Compromisso firmado entre o estagiário, a instituição de ensino e a parte concedente do estágio;

$\S 2^{\circ} \mathrm{A}$ instituição de educação profissional e tecnológica interessada em ofertar programas na modalidade de aprendizagem profissional deverá proceder ao registro eletrônico no Cadastro Nacional de Aprendizagem do Ministério do Trabalho.;

$\S 3^{\circ}$ A duração do contrato de aprendizagem deverá coincidir com o termo inicial e final do programa de aprendizagem.

$\S 4^{\circ}$ Excepcionalmente, quando o curso técnico tiver duração superior à do programa de aprendizagem, o contrato poderá ser celebrado após o início do curso, observadas as seguintes condições:

I - o início e término do contrato de aprendizagem e do programa de aprendizagem deverão coincidir com o início e término dos respectivos módulos;

II - o contrato deverá englobar o mínimo de módulo (s) que assegurarem a formação técnico profissional metódica completa, necessária para a certificação do curso de aprendizagem correspondente a uma ocupação prevista na Classificação Brasileira de Ocupações - CBO; III - a carga horária teórica não poderá ser inferior a quatrocentas horas.

IV - A aplicação da exceção prevista neste parágrafo restringe-se à formação ofertada em escolas técnicas públicas e no âmbito da gratuidade dos Serviços Nacionais de Aprendizagem.

$\S 5^{\circ}$ A formação profissional como parte integrante do contrato de aprendizagem deve ser gratuita para o aprendiz.

Art. 13. Ao elaborar os programas de aprendizagem, as entidades formadoras e empresas responsáveis pela contratação dos aprendizes devem observar as proibições de trabalho aos menores de 18 anos nas atividades descritas na Lista das Piores Formas de Trabalho Infantil - Lista TIP, aprovada pelo Decreto $n^{\circ} 6.481$ de 12 de junho de 2008. (Alterado pela portaria 634 de 09 de agosto de 2018)

Art. 14. A autorização de utilização de metodologia de educação à distância para a aprendizagem e sua inserção no CNAP restringe-se a cursos e programas em locais em que: (Alterado pela portaria 634 de 09 de agosto de 2018)

I - o potencial de contração de aprendizes no município seja inferior a 25 no setor econômico (comércio, serviços, indústria, agricultura e transporte, entre outros);

II - sua implantação imediata não seja possível em razão de inexistência de estrutura educacional adequada para a aprendizagem. 
Parágrafo único. As propostas de programas de aprendizagem à distância serão avaliadas pelo MTE, e autorizada sua inserção no CNAP quando adequadas ao estabelecido nesta Portaria e aos termos do Anexo II.

Art. 15. Para inserção no CNAP dos programas de aprendizagem desenvolvidos em parceria devem participar, no máximo, duas entidades que, em conjunto, inscreverão o programa no CNAP, no endereço eletrônico previsto no art. $3^{\circ}$, com justificativa da necessidade da parceria, detalhamento da participação e responsabilidade de cada uma das entidades e especificação das respectivas atribuições na execução do programa. (Alterado pela portaria 634 de 09 de agosto de 2018)

$\S 1^{\circ}$ A análise da SPPE para autorização da validação da parceria no CNAP se fundamentará nas informações da inscrição do programa de aprendizagem e naquelas constantes do Cadastro referentes às entidades parceiras.

$\S 2^{\circ}$ A entidade parceira que assumir a condição de empregador fica responsável pelo ônus decorrente da contratação do aprendiz, sem prejuízo da responsabilidade subsidiária da outra entidade parceira e do estabelecimento responsável pelo cumprimento da cota de aprendizagem.

$\S 3^{\circ}$ A parceria não será autorizada se a participação e a responsabilidade de uma entidade limitar-se ao registro e anotação da CTPS do aprendiz.

$\S 4^{\circ}$ Em caso de constatação, pela fiscalização, de desvirtuamento da parceria, a aprendizagem será descaracterizada, devendo ser enviado relatório para a SPPE, nos moldes do art. $7^{\circ}$ desta Portaria, para fins de suspensão do programa de aprendizagem feito em parceria e da autorização de inserção das entidades no CNAP.

Art. 16. A entidade qualificada em formação técnico-profissional inserida no CNAP poderá desenvolver programa de aprendizagem em município diverso de sua sede, desde que cadastre no CNAP suas filiais e unidades sem CNPJ e respectivos programas para o município em que irá atuar. (Alterado pela portaria 634 de 09 de agosto de 2018)

$\S 1^{\circ} \mathrm{O}$ cadastro das filiais, unidades sem CNPJ e respectivos programas deverá atender a todos os requisitos constantes nesta portaria.

$\S 2^{\circ}$ A filial ou unidade sem CPNJ que não possua registro no CMDCA poderá atuar desde que apresente o registro do CMDCA da entidade matriz, bem como efetue a inscrição do programa no CMDCA do município em que o mesmo será ministrado.

Art. 16-A. A formação profissional teórica, ministrada pelas entidades relacionadas no Art. 430 da CLT, deverá ser inteiramente gratuita para o aprendiz, sendo vedada a cobrança de 
matrícula, mensalidades, material didático, uniforme ou ônus de qualquer natureza. (Alterado pela portaria 634 de 09 de agosto de 2018)

Art. 17. Os contratos de aprendizagem efetuados com base em programa validados até a publicação desta Portaria devem ser executados até o seu término, sem necessidade de adequação (Alterado pela portaria 1005 de 01 de julho de 2013)

Art. 18. Esta Portaria entra em vigor 120 dias após a data de sua publicação. A eficácia do Art. $4^{\circ}$, quanto à assinatura digital do termo de compromisso, fica suspensa até o lançamento da Plataforma Mais Aprendiz, devendo neste ínterim ser utilizada a metodologia na plataforma juventude web. (Alterado pela portaria 634 de 09 de agosto de 2018)

I - para as entidades mencionadas no caput do Art. 430 da CLT, a eficácia dos $\S 3^{\circ}$ do art. 1, art. $3^{\circ}$ e art. 6- A fica condicionada ao funcionamento da plataforma Mais Aprendiz.

Art. 19. Revogam-se as Portarias M.T.E n ${ }^{\circ}$ 615, de 13 de dezembro de 2007; n ${ }^{\circ} 2.755$, de 23 de novembro de $2010 ; \mathrm{n}^{\mathrm{o}} 1681,16$ de agosto de 2011 e $\mathrm{n}^{\mathrm{o}} 2185$ de 05 de novembro de 2009. (Alterado pela portaria 1005 de 01 de julho de 2013)

\section{CAIO VIEIRA DE MELLO}

